\title{
Analysis on a Kinetic Theoretical Model of the Straight-Curved Pipe Conveying Fluid
}

\author{
Hua-bin Wen \\ School of Mechanics and Engineering, Southwest Jiaotong University, Chengdu 610031, China. \\ School of Mechanical Engineering, Sichuan University of Science and Engineering, Zigong 643000, China.
}

\section{Yi-ren Yang}

School of Mechanics and Engineering, Southwest Jiaotong University, Chengdu 610031, China.

\author{
Yun-dong Li \\ School of Mechanical Engineering, Sichuan University of Science and Engineering, Zigong 643000, China. \\ Sichuan Province University Key Laboratory of Bridge Non-destruction Detecting and Engineering Computing, \\ Zigong 643000, China.
}

\author{
Yun Huang \\ School of Mechanics and Engineering, Southwest Jiaotong University, Chengdu 610031, China.
}

(Received 26 October 2017; accepted 12 February 2018)

\begin{abstract}
A kinetic theoretical model for the straight-curved pipe conveying fluid was proposed and studied in this paper. Firstly, the new equations of static equilibrium and motion about equilibrium position were derived by applying perturbation method to the motion equations of the curved pipe conveying fluid. Then, the kinetic equations of the straight pipe were derived by ignoring the terms containing the curvature of the curved pipe in these equations. Subsequently, considering different factors, four segmental kinetic theoretical models of the straight-curved pipe were built. Lastly, based on the present theoretical models and finite element method, the static deformations and natural frequencies of the pipes with three typical boundary conditions were simulated. The simulation results show that the applicability of these kinetic theoretical models is closely related to the boundary conditions: 1) For the pipes with any one of three boundary conditions, the geometrical non-linearity and the nonlinear force caused by the deformation of straight pipe segment, have a great effect on the static deformation of the pipes, while they have little effect on the natural frequencies of the pipes. 2) When the natural frequencies of the pinned-pinned pipe or the pinned-sliding bearing-pinned pipe are solved, the static deformation of the pipes must be considered. 3) When the natural frequencies of the pinned-pinned-pinned pipe are solved, the static deformation of the pipe can be ignored.
\end{abstract}

\section{NOMENCLATURE}

$x, y \quad$ Direction along the tangent and the principal normal of the centerline of the pipe element respectively

$u, v \quad$ Displacements in tangent and normal direction respectively

$L$

$A_{i}$

$A_{t}$

$P_{i}$

$Q_{x}$

$R$

EI

$U$

$M_{t}$

$M_{f}$

\section{INTRODUCTION}

Flow-induced vibration of the pipe conveying fluid is a difficult problem in many industrial projects. It contains so many dynamic phenomena and has attracted the attention of many scholars. For the past decades, scholars at home and abroad have carried out a large number of related researches and obtained so many fruitful results. From the perspective of pipe geometries, the previous literatures mainly focused on the vibration research of single-configuration pipes, such as straight pipes or curved pipes separately. However, flow-induced vibration of multi-conformational pipe conveying fluid has been studied little. In actual project, the pipe conveying fluid is always composed of straight pipe segments and curved pipe segments. Therefore, the geometric model of multi-configuration pipe is closer to engineering practice, and its research results have more practical significance.

According to the different boundary conditions, straight pipe can be divided into two kinds: pipes supported at both ends and cantilever pipes. The two forms of pipe have differ- 
ent mechanical characteristics, and the reasons of instability caused by fluid in the pipes are also different. Based on the linear theory, Paidoussis, ${ }^{1}$ Dai, Wang, Qian, et al., ${ }^{2}$ Wen, Yang, $\mathrm{Li}$, et al. ${ }^{3}$ studied the stability of straight pipe conveying fluid supported at both ends. The results show that with increasing the flow velocity of fluid, the pipe buckles firstly, and then loses stability with coupled-mode flutter. Rahmati, Mirdamadi, et al. ${ }^{4}$ dealt with the investigation of probabilistic stability of pipes conveying fluid with stochastic flow velocity. The results delineate that the critical mean flow velocity of fluid is closely related to the power spectral density of the random velocity, the boundary condition, viscoelastic damping and mass ratio. Holmes $^{5,6}$ studied the stability of straight pipes supported at both ends by using the nonlinear theory and found that the pipe supported at both ends will not flutter if the nonlinear force caused by pipe deformation was taken into account. Łuczko and Czerwiński ${ }^{7}$ and Czerwiński and Łuczko ${ }^{8}$ analyzed the non-planar vibration of a statically deformed pipe conveying fluid with experiments and numerical simulations. The results show that the pipe's curvature and geometrical nonlinearities result in coupling of in-plane and out-plane vibration, which in certain conditions give rise to non-planar vibrations. As for cantilever pipes conveying fluid, fluid in the pipe could cause the pipe flutter. ${ }^{3,9}$ The motion of cantilever pipe conveying fluid is very complex when some nonlinear factors are considered, and the change of any parameter of the system could result in a great change of the motion of pipe. ${ }^{10-12}$

The history of the study on the curved pipe conveying fluid has not been long before. Chen has derived the in-plane vibration equation of the curved conveying pipe by using Hamilton's principle ${ }^{13}$ and Newton's method,,${ }^{14}$ and analyzed the stability of the curved pipe. The results show that: 1) with increasing the flow velocity of the fluid, the curved pipe supported at both ends has buckling instability firstly; 2) the buckling form of the cantilever curved pipe is closely related to the subtended angle of the curved pipe: under the influence of the internal flow fluid, if the ratio between the subtended angle and $2 \pi$ is less than 0.25 , the pipe only has flutter instability, and if the ratio is larger than 0.25 the pipe has buckling instability first. Misra, Paidoussis and Van ${ }^{15,16}$ derived the motion equations of the curved pipe conveying fluid with complex shape by using Newton method. In order to simplify the calculation, these equations were linearized to establish the equations of static equilibrium of the curved pipe conveying fluid and the equations governing the motion of the curved pipe conveying fluid about the equilibrium position. It should be noted that the motion equations about equilibrium position can be degenerated into the equations in literatures ${ }^{13,14}$ by ignoring the parameters about the equilibrium state. The results show that if the static deformation of pipe was considered, the curved pipe supported at both ends could not lose the stability; as for the buckling form of the semi-circular cantilever curved pipe conveying fluid, the predicted results of Misra's and Chen's theoretical models are qualitatively consistent. So Chen's theoretical model is still used by other scholars to study the kinetic behavior of the cantilever curved pipe conveying fluid, such as $\mathrm{Ni}$, Wang, Qian, ${ }^{17}$ Wang, $\mathrm{Ni}$, Huang,,${ }^{18,19}$ Wang, $\mathrm{Ni}^{20}$ and Wang. ${ }^{21}$ Jung and Chung ${ }^{22}$ added the terms about the geometrical non-linearity of the pipe in the equations of static equi- librium derived by Misra, Paidoussis and Van, ${ }^{15,16}$ and studied the stability of the curved pipe supported at both ends. The result shows that when the flow velocity of the fluid is large, the terms about geometrical non-linearity of the pipe should be considered to avoid discontinuities in the pipe static deformation.

There is little reported literature on the vibration problem of the three-dimensional curved pipe conveying fluid, and the existing literature is limited to the analysis on linear vibration characteristics of the system. Koo and Park ${ }^{23}$ and Koo and $\mathrm{Yoo}^{24}$ studied the vibration performance and stability of the three-dimensional pipe conveying fluid, and obtained the amplitude-frequency characteristic of the pipe with the motion equations of the straight pipe, based on the idea of "replacing curves with straight". Dai, Wang, et al. ${ }^{2}$ thought that the equations in literatures ${ }^{23,24}$ didn't consider the influence of the static axial force of pipe, so the conclusions of the related researches could be doubted. Therefore, the static axial force was introduced into the equation of motion of the curved pipe segment, and the vibration performance of the three-dimensional pipe conveying fluid in the literature ${ }^{24}$ was recalculated. Besides, there is little literature on the vibration problem of the three-dimensional curved pipe conveying fluid.

In summary, as for the pipe conveying fluid containing the configuration characteristics of straight pipe segment and the curved pipe segment, its vibration performance may be closely related to the nonlinear force caused by the deformation of the straight pipe segment, static deformation of the pipe and geometrical non-linearity of the pipe. However, the theoretical models in the literatures ${ }^{23,24}$ didn't consider these factors, and the theoretical model in the literature ${ }^{2}$ just considered the static axial force generated by the static deformation of the pipe. Therefore, the current kinetic theoretical model of the multiconfiguration pipe conveying fluid should be optimized. It is necessary to further clarify the internal connections between the vibration characteristics of pipe and the factors such as the nonlinear force caused by the deformation of the straight pipe segment, static deformation of the pipe and geometrical nonlinearity of the pipe.

In this paper, a kinetic theoretical model of the straightcurved pipe conveying fluid is studied. The geometrical configuration of the straight-curved pipe contains straight pipe configuration and curved pipe configuration. Firstly, the new equilibrium equations, the motion equations of the curved pipe conveying fluid about the equilibrium position were derived. Then, the equilibrium equations of the straight pipe conveying fluid and the motion equations of the straight pipe conveying fluid about the equilibrium position were derived by ignoring the terms that contained the curvature of the curved pipe in these equations. Subsequently, the four segmental kinetic theoretical models of the straight-curved pipe conveying fluid were built according to different factors. Following, the equations of the present theoretical models are analyzed by FEM, and the finite element forms of the equations are derived. Lastly, the static deformation and generalized eigenvalues of straightcurved pipe conveying fluid with several typical boundary conditions are solved. With the comparative analysis of the calculated results, the applicability of the four theoretical models is studied and the stability of the straight-curved pipe conveying 
fluid under various typical constraints is predicted.

\section{THEORETICAL MODEL OF THE STRAIGHT-CURVED PIPE}

The geometry configuration of the straight-curved pipe conveying fluid is shown in Fig. 1. The total length of the pipe is $L$, and the length of the straight pipe segment is $L_{1}$, so as the length of the curved pipe segment is $L_{2}$, and the radius of the curved pipe is $R$. Point $A, B$ and $C$ are the left end of the straight pipe segment, the right end of the curved pipe segment, and the connection point between the straight pipe segment and the curved pipe segment respectively.

In this paper, the segmental kinetic theoretical model of straight-curved pipe conveying would be established with the theoretical model of straight pipe conveying fluid and the curved pipe conveying fluid, which can embody the geometry features of straight pipe and curved pipe well.

\subsection{The Theoretical Model of the Curved Pipe Segment}

Misra, Paidoussis and Van ${ }^{15}$ derived the equations of motion for a curved pipe conveying fluid with complex shape by using Newton's method. Ignoring the equation of motion about outof-plane motion, and ignoring some other factors such as outpipe fluid, gravity and structural damping, the kinetic equation could be obtained:

$$
\begin{aligned}
& -\left(A_{i} P_{i}-Q_{x}\right)^{\prime}+(E I / R)\left(v^{\prime \prime \prime}+u^{\prime \prime} / R\right)+ \\
& (1 / R)\left[\left(A_{i} P_{i}-Q_{x}\right)\left(v^{\prime}+u / R\right)\right]+\left(M_{f} U^{2} / R\right)\left(v^{\prime}+u / R\right)- \\
& \quad M_{f} U\left(\dot{u}^{\prime}-\dot{v} / R\right)-\left(M_{t}+M_{f}\right) \ddot{u}=0 ; \\
& E I\left(v^{\prime \prime \prime \prime}+u^{\prime \prime \prime} / R\right)+\left[\left(A_{i} P_{i}-Q_{x}\right)\left(v^{\prime}+u / R\right)\right]^{\prime}+ \\
& (1 / R)\left(A_{i} P_{i}-Q_{x}\right)+M_{f} U^{2}\left(v^{\prime \prime}+u^{\prime} / R+1 / R\right)+ \\
& \quad 2 M_{f} U\left(\dot{v}^{\prime}+\dot{u} / R\right)+\left(M_{t}+M_{f}\right) \ddot{v}=0 ;
\end{aligned}
$$

where the prime represents a derivative with respect to $s$, and the superposed dot represents a derivative with respect to time.

The following dimensionless variables and parameters are introduced:

$$
\begin{aligned}
\xi & =\frac{s}{L} \\
\eta_{1} & =\frac{u}{L} \\
\eta_{2} & =\frac{v}{L} \\
\tau & =\frac{t}{L^{2}}\left(\frac{E I}{M_{f}+M_{t}}\right)^{1 / 2} ; \\
\bar{u} & =L U\left(\frac{M_{f}}{E I}\right)^{1 / 2} ; \\
\theta & =\frac{L}{R} ; \\
\mathcal{A} & =\frac{A_{t} L^{2}}{I} \\
\beta & =\frac{M_{f}}{M_{f}+M_{t}} \\
\Pi_{p} & =\frac{A_{i} P_{i} L^{2}}{E I}
\end{aligned}
$$

$$
\Pi=\frac{\left(A_{i} P_{i}-Q_{x}\right) L^{2}}{E I} .
$$

Substituting Eq. (3) into Eqs. (1) and (2), the dimensionless equations of motion for the in-plane motion of the curved pipe are:

$$
\begin{gathered}
-\Pi^{\prime}+\theta\left(\eta_{2}^{\prime \prime \prime}+\theta \eta_{1}^{\prime \prime}\right)+\Pi \theta\left(\eta_{2}^{\prime}+\theta \eta_{1}\right)+\bar{u}^{2} \theta\left(\eta_{2}^{\prime}+\theta \eta_{1}\right)- \\
\beta^{1 / 2} \bar{u}\left(\dot{\eta}_{1}^{\prime}-\theta \dot{\eta}_{2}\right)-\ddot{\eta}_{1}=0 \\
\left(\eta_{2}^{\prime \prime \prime \prime}+\theta \eta_{1}^{\prime \prime \prime}\right)+\left[\Pi\left(\eta_{2}^{\prime}+\theta \eta_{1}\right)\right]^{\prime}+\Pi \theta+\bar{u}^{2}\left(\eta_{2}^{\prime \prime}+\theta \eta_{1}^{\prime}+\theta\right)+ \\
2 \beta^{1 / 2} \bar{u}\left(\dot{\eta}_{2}^{\prime}+\theta \dot{\eta}_{1}\right)+\ddot{\eta}_{2}=0
\end{gathered}
$$

It is assumed that the displacement consists of static term and disturbance term, namely as follows,

$$
\begin{aligned}
& \eta_{1}=\eta_{1 s}+\eta_{1 d} \\
& \eta_{2}=\eta_{2 s}+\eta_{2 d}
\end{aligned}
$$

where the subscript $s$ indicates the static quantity, and the subscript $d$ indicates the disturbance quantity.

According to the extensible theory in literature, ${ }^{16}$ the axial force of the curved pipe segment is:

$$
Q_{x}=E A_{t}\left(\frac{\partial u}{\partial s}-\frac{v}{R}\right) .
$$

By substituting Eq. (7) into Eqs. (4) and (5), and ignoring the time-related terms, the static equilibrium equation of the curved pipe conveying fluid can be derived:

$$
\begin{gathered}
-\mathcal{A}\left(\eta_{1 s}^{\prime}-\theta \eta_{2 s}\right)^{\prime}-\theta\left(\eta_{2 s}^{\prime \prime \prime}+\theta \eta_{1 s}^{\prime \prime}\right)-\theta \Pi_{p}\left(\eta_{2 s}^{\prime}+\theta \eta_{1 s}\right)- \\
\bar{u}^{2} \theta\left(\eta_{2 s}^{\prime}+\theta \eta_{1 s}\right)+\mathcal{A} \theta\left(\eta_{1 s}^{\prime}-\theta \eta_{2 s}\right)\left(\eta_{2 s}^{\prime}+\theta \eta_{1 s}\right)=0 ; \\
\left(\eta_{2 s}^{\prime \prime \prime \prime}+\theta \eta_{1 s}^{\prime \prime \prime}\right)+\left(\Pi_{p}+\bar{u}^{2}\right)\left(\eta_{2 s}^{\prime}+\theta \eta_{1 s}\right)-\mathcal{A} \theta\left(\eta_{1 s}^{\prime}-\theta \eta_{2 s}\right)+ \\
\theta\left(\Pi_{p}+\bar{u}^{2}\right)-\mathcal{A}\left[\left(\eta_{1 s}^{\prime}-\theta \eta_{2 s}\right)\left(\eta_{2 s}^{\prime}+\theta \eta_{1 s}\right)\right]^{\prime}=0
\end{gathered}
$$

Equations (8) and (9) contain nonlinear terms about geometric nonlinear deformations. If the terms about geometrical non-linearity are ignored, Eqs. (8) and (9) can be degenerated into the linear static equilibrium equations derived in the literature. $^{16}$

Substituting Eq. (6) into Eqs. (4) and (5), the equations of motion of the curved pipe conveying fluid about the equilibrium position can be obtained as following:

$$
\begin{aligned}
& -\theta\left(\eta_{2 d}^{\prime \prime \prime}+\theta \eta_{1 d}^{\prime \prime}\right)-\theta \Pi_{s}\left(\eta_{2 d}^{\prime}+\theta \eta_{1 d}\right)+ \\
& \mathcal{A} \theta\left(\eta_{2 s}^{\prime}+\theta \eta_{1 s}\right)\left(\eta_{1 d}^{\prime}-\theta \eta_{2 d}\right)-\mathcal{A}\left(\eta_{1 d}^{\prime \prime}-\theta \eta_{2 d}^{\prime}\right)- \\
& \quad \bar{u}^{2} \theta\left(\eta_{2 d}^{\prime}+\theta \eta_{1 d}\right)+\beta^{1 / 2} \bar{u}\left(\dot{\eta}_{1 d}^{\prime}-\theta \dot{\eta}_{2 d}\right)+\ddot{\eta}_{1 d}=0 \\
& \left(\eta_{2 d}^{\prime \prime \prime \prime}+\theta \eta_{1 d}^{\prime \prime \prime}\right)+\left[\Pi_{s}\left(\eta_{2 d}^{\prime}+\theta \eta_{1 d}\right)\right]^{\prime}- \\
& \mathcal{A}\left[\left(\eta_{2 s}^{\prime}+\theta \eta_{1 s}\right)\left(\eta_{1 d}^{\prime}-\theta \eta_{2 d}\right)\right]^{\prime}-\mathcal{A} \theta\left(\eta_{1 d}^{\prime}-\theta \eta_{2 d}\right)+ \\
& \quad \bar{u}^{2}\left(\eta_{2 d}^{\prime \prime}+\theta \eta_{1 d}^{\prime}\right)+2 \beta^{1 / 2} \bar{u}\left(\dot{\eta}_{2 d}^{\prime}+\theta \dot{\eta}_{1 d}\right)+\ddot{\eta}_{2 d}=0
\end{aligned}
$$

where $\Pi_{s}$ is the static value of the axial force, and its expression is

$$
\Pi_{s}=\Pi_{p}-\mathcal{A}\left(\eta_{1 s}^{\prime}-\theta \eta_{2 s}\right) .
$$

\subsection{The Theoretical Model of the Straight Pipe Segment}

The straight pipe can be regarded as the curved pipe with the curvature being 0 , that is, $\theta=0$. When the axial displacement 
of the two ends of the straight pipe segment are constrained, the axis of the pipe will extend due to the bending deformation, and then produce the added axial force, so the axial force of the pipe is

$$
Q_{x}=E A_{t}\left(\frac{\partial u}{\partial x}+\frac{1}{2}\left(\frac{\partial v}{\partial x}\right)^{2}\right) .
$$

Then the following static equilibrium equations of the straight pipe conveying fluid and the equations of motion of the straight pipe conveying fluid about the equilibrium position can be derived.

$$
\begin{gathered}
-\mathcal{A}\left(\eta_{1 s}^{\prime \prime}+\eta_{2 s}^{\prime} \eta_{2 s}^{\prime \prime}\right)=0 \\
\eta_{2 s}^{\prime \prime \prime \prime}+\left(\Pi_{p}+\bar{u}^{2}\right) \eta_{2 s}^{\prime \prime}-\mathcal{A}\left(\eta_{1 s}^{\prime} \eta_{2 s}^{\prime}\right)^{\prime}-\frac{3 \mathcal{A}}{2} \eta_{2 s}^{\prime 2} \eta_{2 s}^{\prime \prime}=0 ; \\
-\mathcal{A} \eta_{1 d}^{\prime \prime}+\ddot{\eta}_{1 d}-\mathcal{A}\left(\eta_{1 d}^{\prime} \eta_{2 d}^{\prime}\right)^{\prime}=0 ; \\
\eta_{2 d}^{\prime \prime \prime \prime}+\bar{u}^{2} \eta_{2 d}^{\prime \prime}+\left(\Pi_{s} \eta_{2 d}^{\prime}\right)^{\prime}+2 \beta^{1 / 2} \bar{u} \dot{\eta}_{2 d}^{\prime}+\ddot{\eta}_{2 d}- \\
\mathcal{A}\left(\eta_{2 s}^{\prime} \eta_{1 d}^{\prime}\right)^{\prime}-\mathcal{A}\left(\eta_{2 s}^{\prime} \eta_{2 s}^{\prime} \eta_{2 d}^{\prime}\right)^{\prime}=0 .
\end{gathered}
$$

Equations (14) and (15) are the static equilibrium equations of the straight pipe conveying fluid, containing the nonlinear terms about the geometrical non-linearity of the pipe and the additional axial force. Equations (16) and (17) are the equations of motion of the straight pipe conveying fluid about the equilibrium position. If the terms about the steady parameters are ignored, Eqs. (16) and (17) can be degenerated into the equation of motion of the straight pipe in the axial and transverse direction derived in literatures. ${ }^{23,24}$ Compared with the theoretical models in the literature, ${ }^{2}$ the steady parameters considered in Eqs. (16) and (17) are more comprehensive, and the calculation results should be more accurate.

\subsection{The Theoretical Model of the Straight- Curved Pipe}

The geometry of the straight-curved pipe conveying fluid is complex, often containing the straight pipe segments and curved pipe segments. Based on the idea of "replacing curves with straight", the vibration problem of the curved pipe can still be solved by using the theoretical model of straight pipe. However, according to the literatures, ${ }^{15,16}$ the initial deformation of the pipe must be considered to study the vibration characteristics and stability of the curved pipe. Otherwise, the calculation result is not reliable. From Eq. (9), it can be seen that the reason for the static deformation of the curved pipe is that there exists an external force term in the equation, that is, $\theta\left(\Pi_{p}+\bar{u}^{2}\right)$. When a straight pipe element is used to simulate a curved pipe element, the external force term will be ignored as in literatures. ${ }^{23,24}$ Literature $^{2}$ added the static axial force in the equations of motion of the straight pipe conveying fluid to consider the effect of the static deformation of the curved pipe, which is the revision of the theoretical model in literatures. $^{23,24}$ However, it is not comprehensive enough to consider the initial deformation of the curved segment. Therefore, in this paper, for the vibration problem of straight-curved pipe conveying fluid, a segmental kinetic theoretical model is established by combining the theoretical models of straight pipe and curved pipe.

\begin{tabular}{|c|c|c|}
\hline $\begin{array}{l}\text { Theoretical } \\
\text { model }\end{array}$ & $\alpha_{1}, \alpha_{2}, \alpha_{3}$ & Remarks \\
\hline Model I & $\alpha_{1}=0$ & The static deformation of pipe is ignored. \\
\hline Model II & $\begin{array}{l}\alpha_{1}=1 \\
\alpha_{2}=0\end{array}$ & $\begin{array}{l}\text { The linear static deformation of pipe is } \\
\text { considered. }\end{array}$ \\
\hline Model III & $\begin{array}{l}\alpha_{1}=1 \\
\alpha_{2}=1 \\
\alpha_{3}=0\end{array}$ & $\begin{array}{l}\text { The geometrical non-linearity of the pipe } \\
\text { is considered. }\end{array}$ \\
\hline Model IV & $\begin{array}{l}\alpha_{1}=1 \\
\alpha_{2}=1 \\
\alpha_{3}=1\end{array}$ & $\begin{array}{l}\text { The geometrical non-linearity of the pipe } \\
\text { and the additional axial force of the } \\
\text { straight pipe segment are considered. }\end{array}$ \\
\hline
\end{tabular}

According to Eqs. (8)-(11), (14)-(17), the following segmental theoretical model of the planar pipe conveying fluid can be obtained.
Table 1. Four theoretical models for calculating the natural frequencies of straight-curved pipe conveying fluid.

\section{(1) Straight pipe segment:}

Equations of static equilibrium of the straight pipe are:

$$
\begin{gathered}
-\mathcal{A}\left(\eta_{1 s}^{\prime \prime}+\alpha_{2} \alpha_{3} \eta_{2 s}^{\prime} \eta_{2 s}^{\prime \prime}\right)=0 ; \\
\eta_{2 s}^{\prime \prime \prime \prime}+\left(\Pi_{p}+\bar{u}^{2}\right) \eta_{2 s}^{\prime \prime}-\alpha_{2} \mathcal{A}\left(\eta_{1 s}^{\prime} \eta_{2 s}^{\prime}\right)^{\prime}-\alpha_{2} \alpha_{3} \frac{3 \mathcal{A}}{2} \eta_{2 s}^{\prime 2} \eta_{2 s}^{\prime \prime}=0 .
\end{gathered}
$$

Equations governing the motion about the static equilibrium position are given by:

$$
\begin{gathered}
-\mathcal{A} \eta_{1 d}^{\prime \prime}+\ddot{\eta}_{1 d}-\alpha_{1} \alpha_{2} \alpha_{3} \mathcal{A}\left(\eta_{2 s}^{\prime} \eta_{2 d}^{\prime}\right)^{\prime}=0 ; \\
\eta_{2 d}^{\prime \prime \prime \prime}+\bar{u}^{2} \eta_{2 d}^{\prime \prime}+\alpha_{1}\left(\Pi_{s s} \eta_{2 d}^{\prime}\right)^{\prime}+2 \beta^{1 / 2} \bar{u} \dot{\eta}_{2 d}^{\prime}+\ddot{\eta}_{2 d}- \\
\alpha_{1} \mathcal{A}\left(\eta_{2 s}^{\prime} \eta_{1 d}^{\prime}\right)^{\prime}-\alpha_{1} \alpha_{2} \alpha_{3} \mathcal{A}\left(\eta_{2 s}^{\prime 2} \eta_{2 d}^{\prime}\right)^{\prime}=0 .
\end{gathered}
$$

\section{(2) Curved pipe segment:}

Equations of static equilibrium of the curve pipe are:

$$
\begin{gathered}
-\mathcal{A}\left(\eta_{1 s}^{\prime}-\theta \eta_{2 s}\right)^{\prime}-\theta\left(\eta_{2 s}^{\prime \prime \prime}+\theta \eta_{1 s}^{\prime \prime}\right)-\theta \Pi_{p}\left(\eta_{2 s}^{\prime}+\theta \eta_{1 s}\right)- \\
\bar{u}^{2} \theta\left(\eta_{2 s}^{\prime}+\theta \eta_{1 s}\right)+\alpha_{2} \mathcal{A} \theta\left(\eta_{1 s}^{\prime}-\theta \eta_{2 s}\right)\left(\eta_{2 s}^{\prime}+\theta \eta_{1 s}\right)=0 \\
\left(\eta_{2 s}^{\prime \prime \prime \prime}+\theta \eta_{1 s}^{\prime \prime \prime}\right)+\left(\Pi_{p}+\bar{u}^{2}\right)\left(\eta_{2 s}^{\prime \prime}+\theta \eta_{1 s}^{\prime}\right)-\mathcal{A} \theta\left(\eta_{1 s}^{\prime}-\theta \eta_{2 s}\right)+ \\
\theta\left(\Pi_{p}+\bar{u}^{2}\right)-\alpha_{2} \mathcal{A}\left[\left(\eta_{1 s}^{\prime}-\theta \eta_{2 s}\right)\left(\eta_{2 s}^{\prime}+\theta \eta_{1 s}\right)\right]^{\prime}=0
\end{gathered}
$$

Equations governing the motion of the curve pipe about the equilibrium position are given by:

$$
\begin{gathered}
-\theta\left(\eta_{2 d}^{\prime \prime \prime}+\theta \eta_{1 d}^{\prime \prime}\right)-\alpha_{1} \theta \Pi_{c s}\left(\eta_{2 d}^{\prime}+\theta \eta_{1 d}\right)+ \\
\alpha_{1} \mathcal{A} \theta\left(\eta_{2 s}^{\prime}+\theta \eta_{1 s}\right)\left(\eta_{1 d}^{\prime}-\theta \eta_{2 d}\right)-\mathcal{A}\left(\eta_{1 d}^{\prime \prime}-\theta \eta_{2 d}^{\prime}\right)- \\
\bar{u}^{2} \theta\left(\eta_{2 d}^{\prime}+\theta \eta_{1 d}\right)+\beta^{1 / 2} \bar{u}\left(\dot{\eta}_{1 d}^{\prime}-\theta \dot{\eta}_{2 d}\right)+\ddot{\eta}_{1 d}=0 ; \\
\left(\eta_{2 d}^{\prime \prime \prime \prime}+\theta \eta_{1 d}^{\prime \prime \prime}\right)+\alpha_{1}\left[\Pi_{c s}\left(\eta_{2 d}^{\prime}+\theta \eta_{1 d}\right)\right]^{\prime}- \\
\alpha_{1} \mathcal{A}\left[\left(\eta_{2 s}^{\prime}+\theta \eta_{1 s}\right)\left(\eta_{1 d}^{\prime}-\theta \eta_{2 d}\right)\right]^{\prime}-\mathcal{A} \theta\left(\eta_{1 d}^{\prime}-\theta \eta_{2 d}\right)+ \\
\bar{u}^{2}\left(\eta_{2 d}^{\prime \prime}+\theta \eta_{1 d}^{\prime}\right)+2 \beta^{1 / 2} \bar{u}\left(\dot{\eta}_{2 d}^{\prime}+\theta \dot{\eta}_{1 d}\right)+\ddot{\eta}_{2 d}=0 .
\end{gathered}
$$

In Eqs. (18)-(25), $\Pi_{s s}$ and $\Pi_{c s}$ are the static value of the axial force of straight pipe segment and the curved pipe segment respectively. Their corresponding expressions can be described as follows respectively:

$$
\begin{aligned}
\Pi_{s s} & =\Pi_{p}-\mathcal{A}\left(\eta_{1 s}^{\prime}+\alpha_{3} \frac{1}{2} \eta_{2 s}^{\prime 2}\right) ; \\
\Pi_{c s} & =\Pi_{p}-\mathcal{A}\left(\eta_{1 s}^{\prime}-\theta \eta_{2 s}\right) .
\end{aligned}
$$

The coefficients $\alpha_{1}, \alpha_{2}, \alpha_{3}$ are introduced in Eqs. (18)-(25) with a value of 0 or 1 . Items that contain $\alpha_{1}$ are terms related to static deformation of the pipe, items that contain $\alpha_{2}$ are 
terms that are related to geometric nonlinearities of the pipe, and items that contain $\alpha_{3}$ are terms that are related to the additional axial forces of the straight pipe segment. According to the values of $\alpha_{1}, \alpha_{2}$ and $\alpha_{3}$, four theoretical models can be established as shown in Table 1.

\section{FINITE ELEMENT ANALYSIS OF MOTION OF STRAIGHT-CURVED PIPE CONVEYING FLUID}

\subsection{Displacement Model of the Pipe Element}

Considering only the in-plane deformation and vibration of the straight-curved pipe conveying fluid, both the straight pipe and the curved pipe can be separated by a beam element with two nodes and six degrees of freedom. Each node has such three degrees of freedom as $\eta_{1}, \eta_{2}$ and $\eta_{2}^{\prime}$, and the displacements in any part of the element can be expressed by the interpolation functions as

$$
\begin{aligned}
& \eta_{1}=\left[N_{1}\right]\{\eta\}^{e} ; \\
& \eta_{2}=\left[N_{2}\right]\{\eta\}^{e} ;
\end{aligned}
$$

where $\left[N_{1}\right]$ and $\left[N_{2}\right]$ are shape functions, $\{\eta\}^{e}$ is the displacement vector quantity of the node.

In order to ensure that the solution of the equation has good calculation accuracy, the displacement function is assumed to be a polynomial as follows:

$$
\begin{aligned}
& \eta_{1}=a_{1}+a_{2} \zeta \\
& \eta_{2}=a_{3}+a_{4} \zeta+a_{5} \zeta^{2}+a_{6} \zeta^{3}
\end{aligned}
$$

where $a_{i}$ is the generalized coordinates, $\zeta$ is the local coordinate of the element.

Then, Eqs (30) and (31) can be converted to

$$
\begin{aligned}
& \eta_{1}=\left[\Phi_{1}\right]\left\{a_{i}\right\} ; \\
& \eta_{2}=\left[\Phi_{2}\right]\left\{a_{i}\right\} ;
\end{aligned}
$$

where

$$
\begin{aligned}
{\left[\Phi_{1}\right] } & =[1, \zeta, 0,0,0,0] ; \\
{\left[\Phi_{2}\right] } & =\left[0,0,1, \zeta, \zeta^{2}, \zeta^{3}\right] ; \\
\left\{a_{i}\right\}^{T} & =\left[a_{1}, a_{2}, a_{3}, a_{4}, a_{5}, a_{6}\right] .
\end{aligned}
$$

Utilizing Eqs. (28), (29), (32) and (33), it can be obtained that:

$$
\begin{aligned}
& \eta_{1}=\left[\Phi_{1}\right][A]^{-1}\{\eta\}^{e} ; \\
& \eta_{2}=\left[\Phi_{2}\right][A]^{-1}\{\eta\}^{e}
\end{aligned}
$$

where

$$
[A]=\left[\begin{array}{cccccc}
1 & 0 & 0 & 0 & 0 & 0 \\
0 & 0 & 1 & 0 & 0 & 0 \\
0 & 0 & 0 & 1 & 0 & 0 \\
1 & \zeta_{e} & 0 & 0 & 0 & 0 \\
0 & 0 & 1 & \zeta_{e} & \zeta_{e}^{2} & \zeta_{e}^{3} \\
0 & 0 & 0 & 1 & 2 \zeta_{e} & 3 \zeta_{e}^{2}
\end{array}\right] .
$$

Here, $\zeta_{e}$ is the length of the pipe element.

\subsection{Analysis of the Static Equilibrium}

Substituting Eqs. (37) and (38) into Eqs. (18), (19), (22) and (23), and considering the two ends of the pipe as hinge constraint or clamped constraint, and with the calculus of variation, the finite element equations calculating the static deformation of the planar pipe conveying fluid can be derived.

The finite element equation of the $i^{\text {th }}$ element of the straight pipe segment is

$$
\left([K]_{s i}^{e}+[K]_{s n i}^{e}\right)\{\eta\}_{s i}^{e}=0
$$

where $[K]_{s i}^{e}$ and $[K]_{s n i}^{e}$ are the linear part and nonlinear part of the stiffness matrix respectively. Their corresponding expressions could be described as follows respectively:

$$
[K]_{s i}^{e}=[A]^{-1 T}\left(\mathcal{A}\left[J_{1}\right]+\left[J_{2}\right]-\left(\Pi_{p}+\bar{u}^{2}\right)\left[J_{3}\right]\right)[A]^{-1} ;
$$

$$
\begin{aligned}
{[K]_{s n i}^{e}=} & {[A]^{-1 T} \int_{0}^{\zeta_{e}}\left\{\alpha_{2} \mathcal{A}\left[\Phi_{2}\right]^{\prime T}\left[\Phi_{1}\right]^{\prime}[A]^{-1}\{\eta\}_{s i}^{e}\left[\Phi_{2}\right]^{\prime}-\right.} \\
& \alpha_{2} \alpha_{3} \mathcal{A}\left[\Phi_{1}\right]^{T}\left[\Phi_{2}\right]^{\prime}[A]^{-1}\{\eta\}_{s i}^{e}\left[\Phi_{2}\right]^{\prime \prime}- \\
& \frac{3}{2} \alpha_{2} \alpha_{3} \mathcal{A}\left[\Phi_{2}\right]^{\prime T}\left[\Phi_{2}\right]^{\prime}[A]^{-1}\{\eta\}_{s i}^{e}\left[\Phi_{2}\right]^{\prime} \\
& {\left.[A]^{-1}\{\eta\}_{\text {si }}^{e}\left[\Phi_{2}\right]^{\prime \prime}\right\} d \zeta[A]^{-1} }
\end{aligned}
$$

The finite element equation of the $i^{\text {th }}$ element of the curved pipe segment is

$$
\left([K]_{s c i}^{e}+[K]_{s c n i}^{e}\right)\{\eta\}_{s i}^{e}=\{F\}_{s c i}^{e}
$$

where $[K]_{s c i}^{e}$ and $[K]_{s c n i}^{e}$ are the linear part and nonlinear part of the stiffness matrix respectively, while $\{F\}_{s c i}^{e}$ is the external load. Their corresponding expressions can be described as follows respectively:

$$
\begin{aligned}
& {[K]_{s c i}^{e}=[A]^{-1 T}\left\{\left(\mathcal{A}+\theta^{2}\right)\left[J_{1}\right]-\theta \mathcal{A}\left[J_{4}\right]+\theta\left[J_{5}\right]-\right.} \\
& \quad \theta\left(\Pi_{p}+\bar{u}^{2}\right)\left(\left[J_{6}\right]+\theta\left[J_{7}\right]\right)+\left[J_{2}\right]+\theta\left[J_{8}\right]+ \\
& \left.\quad\left(\Pi_{p}+\bar{u}^{2}\right)\left(\left[J_{9}\right]+\theta\left[J_{10}\right]\right)-\mathcal{A} \theta\left(\left[J_{10}\right]-\theta\left[J_{11}\right]\right)\right\}[A]^{-1}
\end{aligned}
$$

$$
\begin{aligned}
& {[K]_{s c n i}^{e}=[A]^{-1 T}\left\{\int_{0}^{\zeta_{e}} \alpha_{2} \mathcal{A}\left(\theta\left[\Phi_{1}\right]^{T}+\left[\Phi_{2}\right]^{\prime T}\right)\right.} \\
& \left.\left(\left[\Phi_{1}\right]^{\prime}-\theta\left[\Phi_{2}\right]\right)[A]^{-1}\{\eta\}_{s i}^{e}\left(\left[\Phi_{2}\right]^{\prime}+\theta\left[\Phi_{1}\right]\right) d \zeta\right\}[A]^{-1} \\
& \{F\}_{s c i}^{e}=-\theta\left(\Pi_{p}+\bar{u}^{2}\right)[A]^{-1 T} \int_{0}^{\zeta_{e}}\left[\Phi_{2}\right]^{T} d \zeta
\end{aligned}
$$

\subsection{Analysis of Motion About Static Equilibrium Position}

\subsubsection{Analysis of Motion of the Straight Pipe Segment About Static Equilibrium Position}

The motion equations, Eqs. (20) and (21), of the straight pipe segment contain the static parameters $\Pi_{s s}$ and $\eta_{2 s}^{\prime}$. For convenience, it is assumed that the static parameters in each element are linear functions, that is,

$$
\begin{gathered}
\Pi_{s s}=a_{1}+a_{2} \xi ; \\
\eta_{2 s}^{\prime}=b_{1}+b_{2} \xi ;
\end{gathered}
$$


where

$$
\begin{aligned}
& a_{1}=\left.\Pi_{s s}\right|_{j}=\Pi_{p}-\left.\mathcal{A}\left(\eta_{1 s}^{\prime}+\frac{1}{2} \alpha_{3} \eta_{2 s}^{\prime 2}\right)\right|_{j} \\
& a_{2}=\left(\left.\Pi_{s s}\right|_{j+1}-\left.\Pi_{s s}\right|_{j}\right) / \xi_{e} \\
& b_{1}=\left.\eta_{2 s}^{\prime}\right|_{j} ; \\
& b_{2}=\left(\left.\eta_{2 s}^{\prime}\right|_{j+1}-\left.\eta_{2 s}^{\prime}\right|_{j}\right) / \xi_{e} .
\end{aligned}
$$

Substituting Eqs. (37)-(38), (47)-(48) into Eqs. (20)-(21), and considering the two ends of the pipe as hinge constraint or clamped constraint, and with the calculus of variation, the finite element equation of the $i^{\text {th }}$ element of the straight pipe segment to calculate the perturbation displacements can be derived, as follows:

$$
[M]_{s d i}^{e}\{\ddot{\eta}\}_{d i}^{e}+[D]_{s d i}^{e}\{\dot{\eta}\}_{d i}^{e}+[K]_{s d i}^{e}\{\eta\}_{d i}^{e}=0
$$

where $[M]_{s d i}^{e},[D]_{s d i}^{e}$ and $[K]_{s d i}^{e}$ are the mass matrix, damping matrix and stiffness matrix of the $i^{\text {th }}$ element respectively, and their corresponding expressions are

$$
\begin{aligned}
& {[M]_{s d i}^{e}=[A]^{-1 T}\left\{\left[J_{7}\right]+\left[J_{11}\right]\right\}[A]^{-1} ;} \\
& {[D]_{s d i}^{e}=2 \beta^{1 / 2} \bar{u}[A]^{-1 T}\left\{\left[J_{13}\right]\right\}[A]^{-1} ;} \\
& {[K]_{s d i}^{e}=[A]^{-1 T}\left\{\mathcal{A}\left[J_{1}\right]+\left[J_{2}\right]+\right.} \\
& \quad \alpha_{1} \alpha_{2} \alpha_{3} \mathcal{A}\left(b_{1}\left[J_{30}\right]+b_{2}\left[J_{31}\right]\right)-\left(\alpha_{1} a_{1}+\bar{u}^{2}\right)\left[J_{3}\right]- \\
& \quad \alpha_{1} a_{2}\left[J_{14}\right]+\alpha_{1} \mathcal{A}\left(b_{1}\left[J_{15}\right]+b_{2}\left[J_{16}\right]\right)+ \\
& \left.\quad \alpha_{1} \alpha_{2} \alpha_{3} \mathcal{A}\left(b_{1}^{2}\left[J_{3}\right]+2 b_{1} b_{2}\left[J_{14}\right]+b_{2}^{2}\left[J_{32}\right]\right)\right\}[A]^{-1} .
\end{aligned}
$$

\subsubsection{Analysis of Motion of the Curved Pipe Segment About Static Equilibrium Position}

The motion equations, Eqs. (24) and (25), of the curved pipe segment contain such static parameters as $\Pi_{c s}, \Pi_{c s}^{\prime}, \eta_{2 s}^{\prime}$ and $\eta_{1 s}$. For convenience, it is assumed that the static parameters in each element are the linear functions. Among them, the parameter $\Pi_{c s}$ is assumed according to Eq. (47), and the corresponding coefficients in the equation at this moment are

$$
\begin{aligned}
& a_{1}=\left.\Pi_{c s}\right|_{j}=\Pi_{p}-\left.\mathcal{A}\left(\eta_{1 s}^{\prime}-\theta \eta_{2 s}\right)\right|_{j} ; \\
& a_{2}=\left(\left.\Pi_{c s}\right|_{j+1}-\left.\Pi_{c s}\right|_{j}\right) / \xi_{e}
\end{aligned}
$$

The parameter $\eta_{2 s}^{\prime}$ is assumed according to Eq. (48), and the parameters $\eta_{1 s}, \Pi_{c s}^{\prime}$ are assumed as Eqs. (55) and (56) respectively.

$$
\begin{gathered}
\eta_{1 s}=c_{1}+c_{2} \xi \\
\Pi_{c s}^{\prime}=d_{1}+d_{2} \xi
\end{gathered}
$$

where

$$
\begin{aligned}
& c_{1}=\left.\eta_{1 s}\right|_{j} ; \\
& c_{2}=\left(\left.\eta_{1 s}\right|_{j+1}-\left.\eta_{1 s}\right|_{j}\right) / \xi_{e} ; \\
& d_{1}=\left.\Pi_{c s}^{\prime}\right|_{j} ; \\
& d_{2}=\left(\left.\Pi_{c s}^{\prime}\right|_{j+1}-\left.\Pi_{c s}^{\prime}\right|_{j}\right) / \xi_{e} ;
\end{aligned}
$$

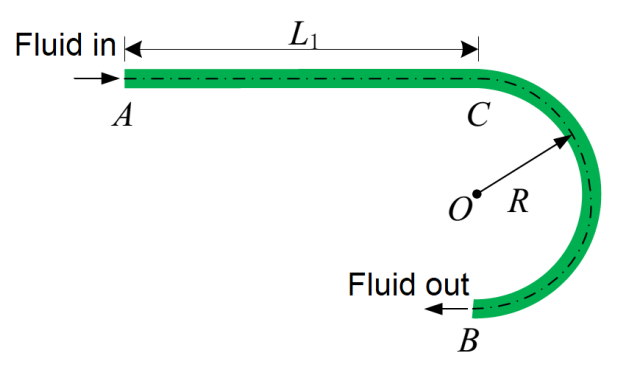

Figure 1. The straight-curved pipe conveying fluid.

Substituting Eqs. (37)-(38), (47)-(48), (55)-(56) into Eqs. (24)-(25), and considering the two ends of the pipe as hinge constraint or clamped constraint, and with the calculus of variation, the finite element equation of the $i^{\text {th }}$ element of the curved pipe segment to calculate the perturbation displacements can be derived as follows:

$$
[M]_{q d i}^{e}\{\ddot{\eta}\}_{d i}^{e}+[D]_{q d i}^{e}\{\dot{\eta}\}_{d i}^{e}+[K]_{q d i}^{e}\{\eta\}_{d i}^{e}=0
$$

where $[M]_{q d i}^{e},[D]_{q d i}^{e}$ and $[K]_{q d i}^{e}$ are the mass matrix, damping matrix and stiffness matrix of the $i^{\text {th }}$ element respectively, and their corresponding expressions are:

$$
\begin{aligned}
& {[M]_{q d i}^{e}=} {[A]^{-1 T}\left(\left[J_{7}\right]+\left[J_{11}\right]\right)[A]^{-1} ; } \\
& {[D]_{q d i}^{e}=} \beta^{1 / 2} \bar{u}[A]^{-1 T}\left(\left[J_{12}\right]-\theta\left[J_{17}\right]+2\left[J_{13}\right]+\right. \\
&\left.2 \theta\left[J_{18}\right]\right)[A]^{-1} ; \\
& {[K]_{q d i}^{e}=} {[A]^{-1 T}\left\{-\alpha_{1} a_{2} \theta\left(\left[J_{19}\right]+\theta\left[J_{20}\right]\right) \theta\left(\left[J_{5}\right]+\theta\left[J_{1}\right]\right)-\right.} \\
& \alpha_{1} a_{1} \theta\left(\left[J_{6}\right]+\theta\left[J_{7}\right]\right)+\alpha_{1} \mathcal{A} \theta\left[\left(b_{1}+\theta c_{1}\right)\left(\left[J_{12}\right]-\theta\left[J_{17}\right]\right)+\right. \\
&\left.\quad\left(b_{2}+\theta c_{2}\right)\left(\left[J_{21}\right]-\theta\left[J_{22}\right]\right)\right] \mathcal{A}\left(\left[J_{1}\right]-\theta\left[J_{4}\right]\right)- \\
& \bar{u}^{2} \theta\left(\left[J_{6}\right]+\theta\left[J_{7}\right]\right)+\left(\left[J_{2}\right]+\theta\left[J_{23}\right]\right)+ \\
& \alpha_{1} d_{1}\left(\left[J_{13}\right]+\theta\left[J_{18}\right]\right)+\alpha_{1} d_{2}\left(\left[J_{24}\right]+\theta\left[J_{25}\right]\right)+ \\
& \alpha_{1} a_{1}\left(\left[J_{9}\right]+\theta\left[J_{10}\right]\right)+\alpha_{1} a_{2}\left(\left[J_{28}\right]+\theta\left[J_{29}\right]\right)+ \\
& \alpha_{1} \mathcal{A}\left(b_{1}+\theta c_{1}\right)\left(\left[J_{15}\right]-\theta\left[J_{26}\right]\right)+ \\
& \quad \alpha_{1} \mathcal{A}\left(b_{2}+\theta c_{2}\right)\left(\left[J_{16}\right]-\theta\left[J_{27}\right]\right)-\mathcal{A} \theta\left(\left[J_{10}\right]-\theta\left[J_{11}\right]\right)+ \\
&\left.\bar{u}^{2}\left(\left[J_{9}\right]+\theta\left[J_{10}\right]\right)\right\}[A]^{-1} .
\end{aligned}
$$

The integral $\left[J_{i}\right]$ in the equations above are referred to the Appendix A.

\section{THE STATIC DEFORMATION AND STABILITY OF STRAIGHT-CURVED PIPE CONVEYING FLUID}

It is assumed that point $A$ in Fig. 1 is the origin of coordinates, then $\xi_{A}=0, \xi_{C}=L_{1} / L, \xi_{B}=1$. The other calculation parameters are: $\xi_{c}=1 / 2, \beta=0.2, \mathcal{A}=10000, \Pi_{p}=0$, $\bar{u} \in[0,3 \pi]$.

Considering the following three boundary conditions: 
(1) pinned-pinned-pinned

$$
\begin{aligned}
\eta_{1}(0, \tau) & =0 \\
\eta_{2}(0, \tau) & =0 \\
\eta_{2}^{\prime \prime}(0, \tau) & =0 \\
\eta_{1}\left(\xi_{c}, \tau\right) & =0 \\
\eta_{2}\left(\xi_{c}, \tau\right) & =0 \\
\eta_{1}(1, \tau) & =0 \\
\eta_{2}(1, \tau) & =0 \\
\theta \eta_{1}^{\prime}(1, \tau)+\eta_{2}^{\prime \prime}(1, \tau) & =0
\end{aligned}
$$

(2) pinned-sliding bearing-pinned

$$
\begin{aligned}
\eta_{1}(0, \tau) & =0 \\
\eta_{2}(0, \tau) & =0 \\
\eta_{2}^{\prime \prime}(0, \tau) & =0 \\
\eta_{2}\left(\xi_{c}, \tau\right) & =0 \\
\eta_{1}(1, \tau) & =0 \\
\eta_{2}(1, \tau) & =0 \\
\theta \eta_{1}^{\prime}(1, \tau)+\eta_{2}^{\prime \prime}(1, \tau) & =0
\end{aligned}
$$

(3) pinned-pinned

$$
\begin{aligned}
\eta_{1}(0, \tau) & =0 \\
\eta_{2}(0, \tau) & =0 \\
\eta_{2}^{\prime \prime}(0, \tau) & =0 \\
\eta_{1}(1, \tau) & =0 \\
\eta_{2}(1, \tau) & =0 \\
\theta \eta_{1}^{\prime}(1, \tau)+\eta_{2}^{\prime \prime}(1, \tau) & =0
\end{aligned}
$$

\subsection{The Simulation Results of the Static Deformation}

Among the four theoretical models in the Table 1, models II-IV contain the equations of static equilibrium, and can be used to calculate the static deformation of the pipe conveying fluid. The finite element equations of the straight pipe element and the curved pipe element, which are corresponding to Eq. (40) and (43) respectively, are derived from the equations of static equilibrium. With the element integration method, the following finite element equation to calculate the static deformation of the straight-curved pipe conveying fluid can be obtained:

$$
\left([K]_{s l}+[K]_{s n}\right)\{\eta\}_{s}=\{F\}_{s} ;
$$

where $[K]_{s l}$ and $[K]_{s n}$ are the linear part and nonlinear part of the total stiffness matrix respectively, and $\{F\}_{s}$ is the nodal load vector.

The equations of static equilibrium of the theoretical model III and IV are nonlinear, and they were solved by NewtonRaphson iterative technique in this paper.

\subsubsection{The Deformation of the Pipe}

The static deformations of the pinned-pinned-pinned pipe are shown in Fig. 2. The difference of the results of the static deformation calculated by theoretical model II, III and IV increases with the increase of the flow velocity. When the flow

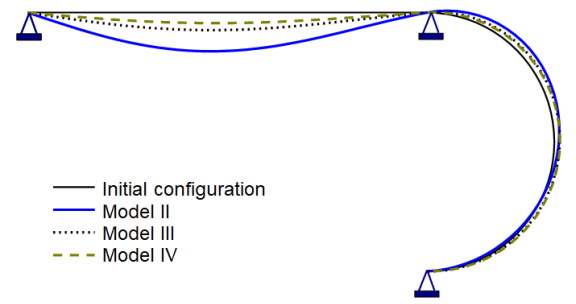

(a) $\bar{u}=2.4 \pi$ (Deformation is magnified by a factor of 10$)$

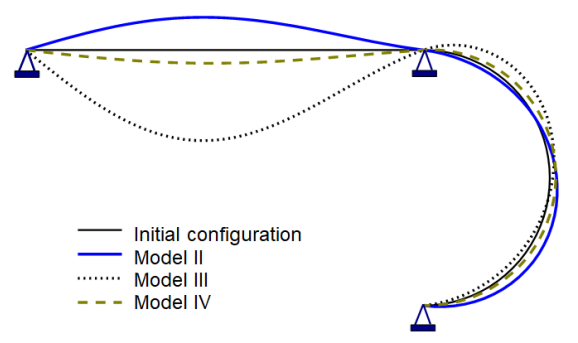

(b) $\bar{u}=2.5 \pi$ (Deformation is magnified by a factor of 5)

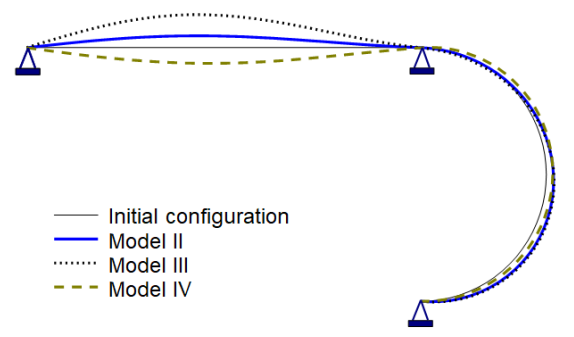

(c) $\bar{u}=2.6 \pi$ (Deformation is magnified by a factor of 5)

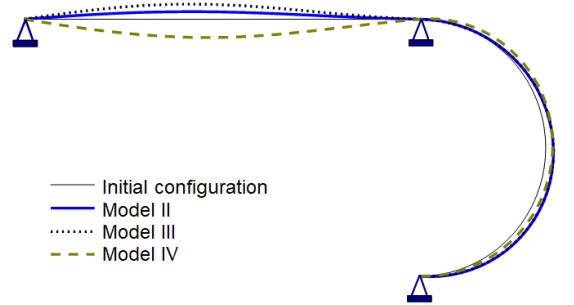

(d) $\bar{u}=2.7 \pi$ (Deformation is magnified by a factor of 5)

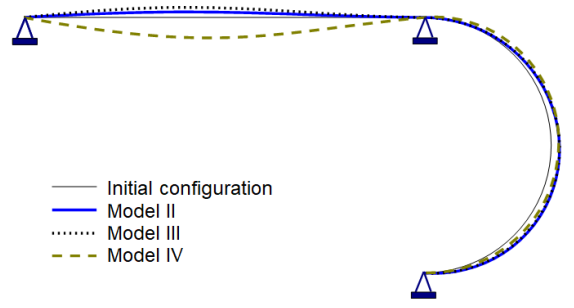

(e) $\bar{u}=2.8 \pi$ (Deformation is magnified by a factor of 5)

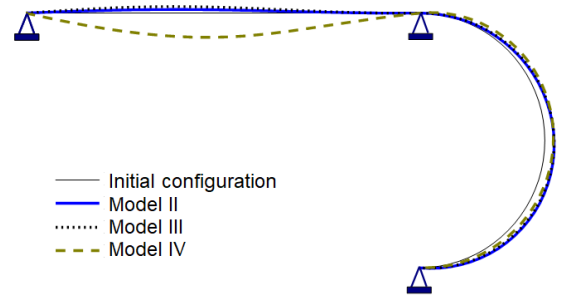

(f) $\bar{u}=3.0 \pi$ (Deformation is magnified by a factor of 5)

Figure 2. The static deformation of the pinned-pinned-pinned pipe. 


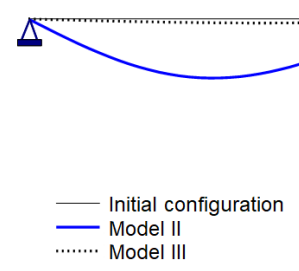

(a) $\bar{u}=2.4 \pi$ (Deformation is magnified by a factor of 5)

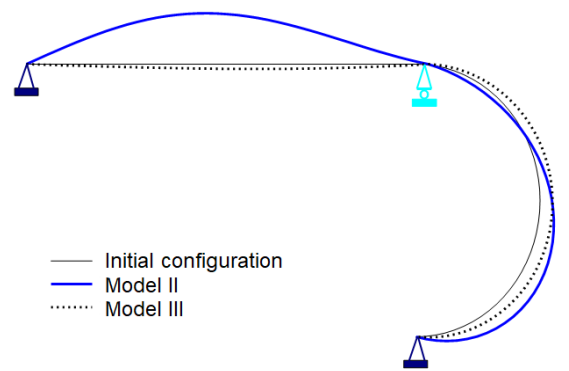

(b) $\bar{u}=2.5 \pi$ (Deformation is magnified by a factor of 5)

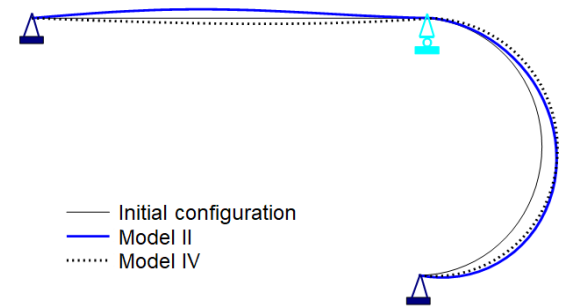

(c) $\bar{u}=2.8 \pi$ (Deformation is magnified by a factor of 5)

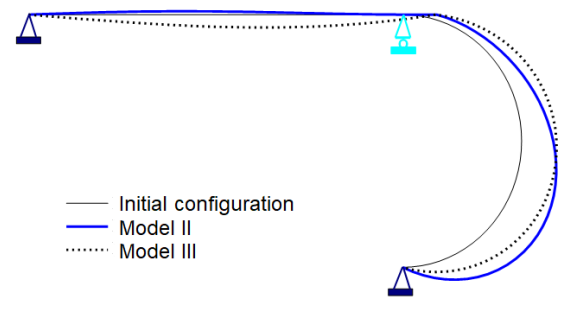

(d) $\bar{u}=3.0 \pi$ (Deformation is magnified by a factor of 10)

Figure 3. The static deformation of the pinned-sliding bearing-pinned pipe.

velocity increases from $\bar{u}=2.4 \pi$ to $2.5 \pi$, a mutation occurs in the static deformation calculated by the theoretical model II, and the direction of bending deformation of the straight pipe segment changes from down to upward, as shown in Fig. 2(a) and 2(b). When the flow velocity increases from $\bar{u}=2.5 \pi$ to $2.6 \pi$, similar mutation occurs in the static deformation calculated by the theoretical model III, as shown in Fig. 2(b) and 2(c). The mutation of the deformation does not appear in the static deformations calculated by the theoretical model IV, and it cannot be explained from the physical perspective. So, when the flow velocity is large, the theoretical model IV is more suitable for the calculation of the static deformation of the pinnedpinned-pinned straight-curved pipe conveying fluid.

The static deformations of the pinned-sliding bearingpinned pipe are shown in Fig. 3. The difference of the static deformation calculated by the theoretical model II and III increases with the increase of the flow velocity. When the flow velocity increases from $\bar{u}=2.4 \pi$ to $2.5 \pi$, a mutation occurs

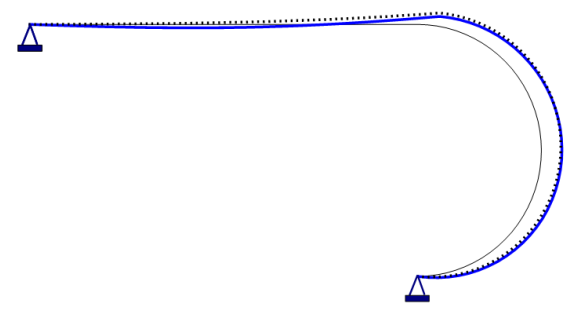

(a) $\bar{u}=1.7 \pi$ (Deformation is magnified by a factor of 20)

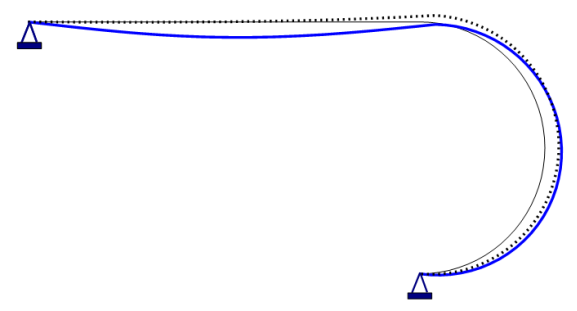

(b) $\bar{u}=2.0 \pi$ (Deformation is magnified by a factor of 10)

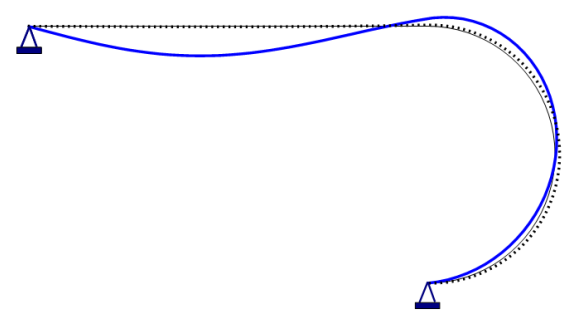

(c) $\bar{u}=2.5 \pi$ (Deformation is magnified by a factor of 2)

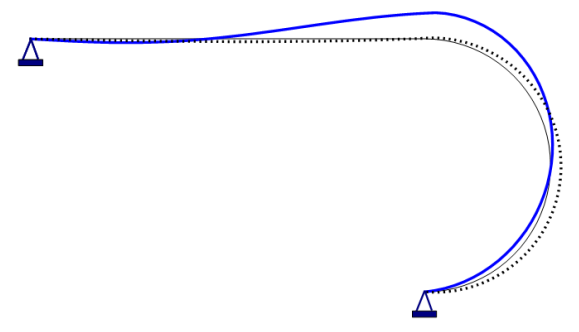

(d) $\bar{u}=3.0 \pi$ (Deformation is magnified by a factor of 3)

Figure 4. The static deformation of the pinned-pinned pipe.

in the static deformation calculated by the theoretical model II, and the direction of bending deformation of the straight pipe segment changes from down to upward, as shown in Fig. 3(a) and 3(b). The mutation of the deformation does not appear in the static deformations calculated by the theoretical model III, and it cannot be explained from the physical perspective. So, when the flow velocity is large, the theoretical model III is more suitable for the calculation of the static deformation of the pinned- sliding bearing -pinned straight-curved pipe conveying fluid.

The static deformations of the pinned-pinned pipe are shown in Fig. 4. The difference of the static deformation calculated by the theoretical model II and III increases with the increase of the flow velocity. The computing results of the theoretical model II show that when the flow velocity is large, the straight pipe segment will have large lateral displacement. However, the computing results of the theoretical model III show that the lateral deformation of the straight pipe segment is always small. So, when the flow velocity is large, the theoretical 
model III is more suitable for the calculation of the static deformation of the pinned-pinned straight-curved pipe conveying fluid.

\subsubsection{The Static Axial Force of the Pipe}

The static axial force of the pipe can be calculated according to the static deformation of the pipe and Eqs. (26) and (27).

With specified flow velocity, the variation curves of the static axial force of the pinned-pinned-pinned pipe varying with the location of the cross section of the pipe are shown in Fig. 5. The additional axial force caused by the bending deformation of the straight pipe segment were not considered in the theoretical model II and III, so only the static axial force of curved pipe segment could be calculated. The theoretical model IV has considered the added additional axial force, so the static axial force of the straight pipe segment and the curved pipe segment could be calculated completely. However, compared with the static axial force of the curved pipe segment, that of the straight pipe segment is very small. For example, if $\bar{u}=3.0 \pi$, the static axial force of the straight pipe segment is about 3.5 (shown in Fig. 5(d)), while that of the curved pipe segment is about 89 (shown in Fig. 5(c)). With specified flow velocity, the static axial force of the curved pipe segment calculated by the theoretical models II-IV always undulate around $-(\bar{u})^{2}$. When the flow velocity is small, the magnitude of the difference between the value of the static axial force of the curved pipe segment calculated by the theoretical models IIIV and $-(\bar{u})^{2}$ is $10^{-1}$. When the flow velocity is large, the magnitude of the difference between the static axial force of the curved pipe segment calculated by the theoretical model II-IV and $-(\bar{u})^{2}$ is $10^{0}$, while the magnitude of the difference between the value of the combined force of the curved pipe section calculated by the theoretical model IV and $-(\bar{u})^{2}$ remains $10^{-1}$.

With specified flow velocity, the variation curves of the static axial force of the pinned-sliding bearing-pinned pipe and the pinned- pinned pipe varying with the location of the cross section of the pipe are shown in Fig. 6 and 7 respectively.

From Figs. 6 and 7, the static axial forces of the pinnedsliding bearing-pinned pipe or the pinned-pinned pipe calculated by theoretical models II and III always undulate around $--(\bar{u})^{2}$. Even when the flow velocity is large, the magnitude of the difference between $-(\bar{u})^{2}$ and the calculated forces remains within $10^{\circ}$. In addition, the axial force of the pipe is not continuous at the connection position. The reasons for this are that: 1) Equation (26) neglected the angular displacement of the straight pipe element. If the angular displacement was taken into account, the equation for calculating static axial force of the straight pipe element should be

$$
\Pi_{s s}=\Pi_{p}-\mathcal{A}\left(\frac{1-\cos \varphi}{\cos \varphi}+\frac{1}{\cos \varphi} \eta_{1 s}^{\prime}\right)
$$

where $\varphi$ is the angular displacement of the straight pipe element. The derivation of this equation refers to Appendix B. When $\varphi$ is small, $\cos \varphi \approx 1$, therefore Eq. (67) could be degenerated into Eq. (26). Obviously, if the angular displacement $\varphi$ of the straight pipe element was taken into account, the calculation results of the static axial force would be decreased. 2) In

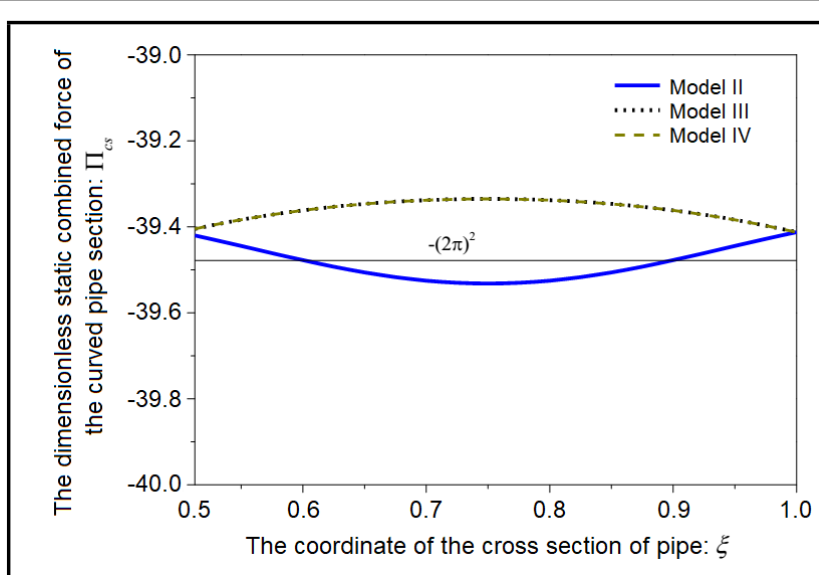

(a) $\bar{u}=2 \pi$

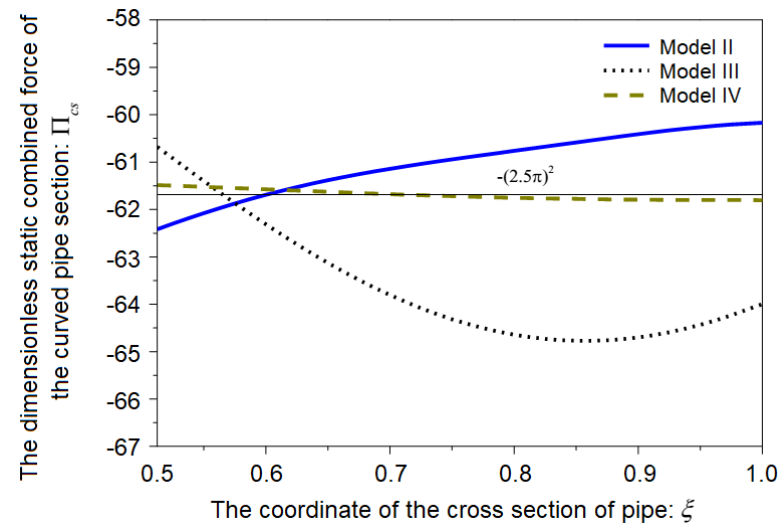

(b) $\bar{u}=2.5 \pi$

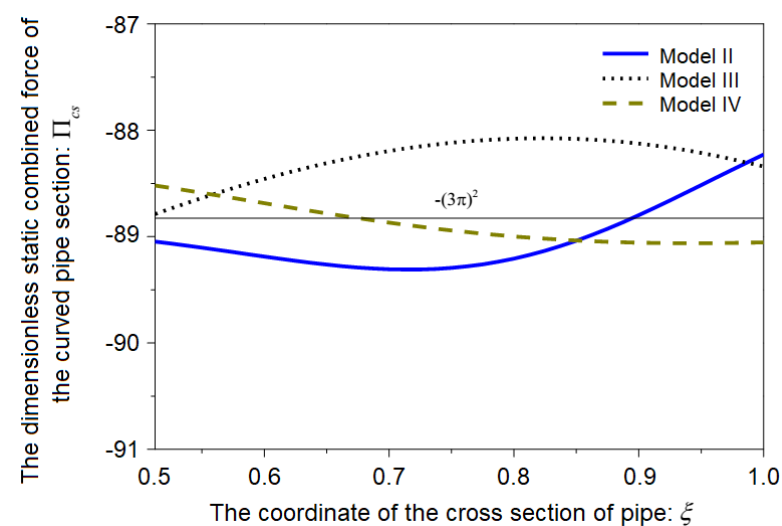

(c) $\bar{u}=3 \pi$

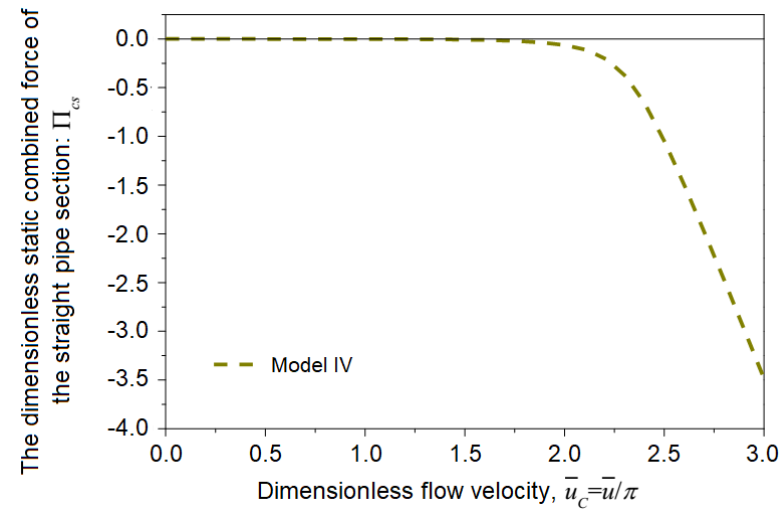

(d)

Figure 5. The variation curve of the static axial force of the pinned-pinnedpinned pipe with the velocity or the location of the cross section of the pipe. 


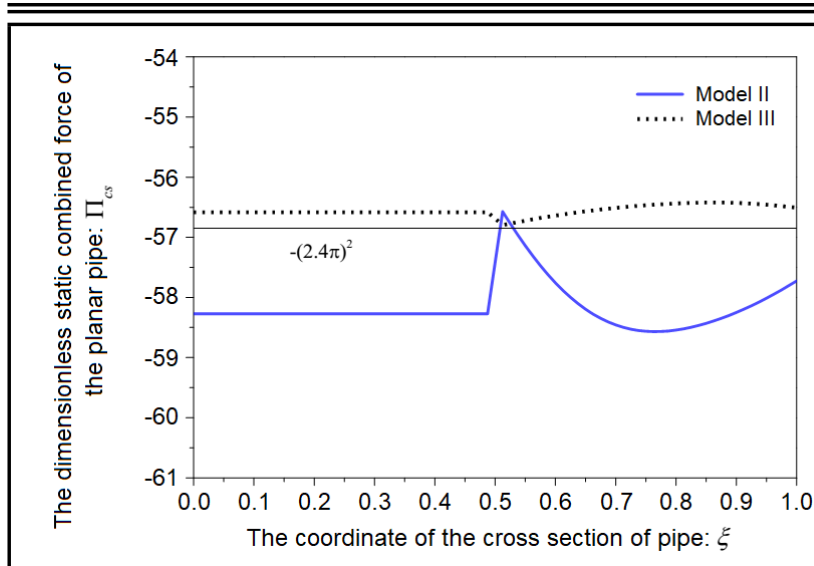

(a) $\bar{u}=2.4 \pi$

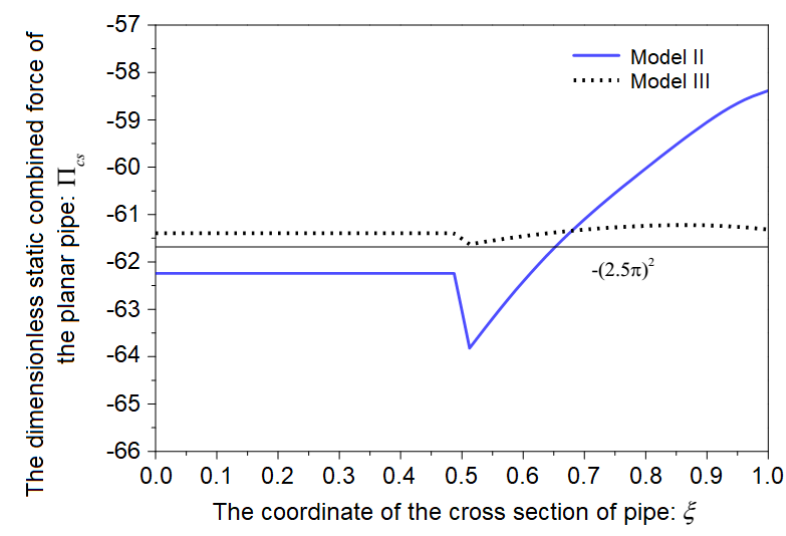

(b) $\bar{u}=2.5 \pi$

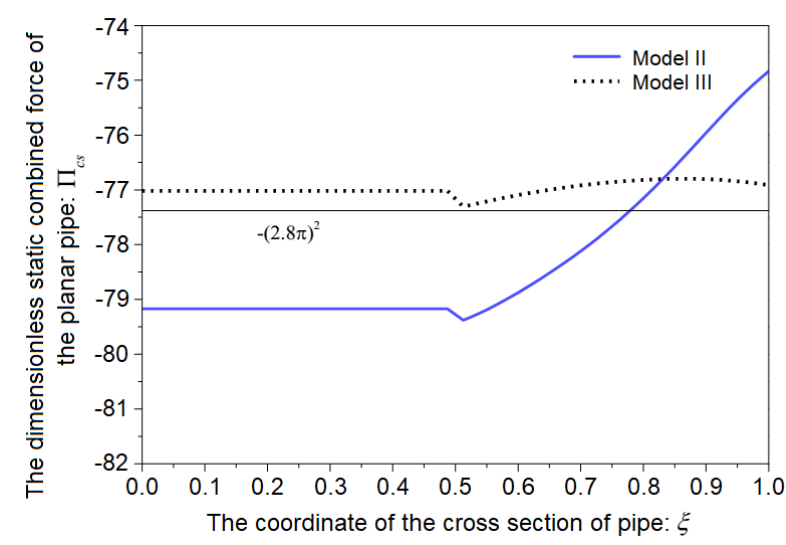

(c) $\bar{u}=2.8 \pi$

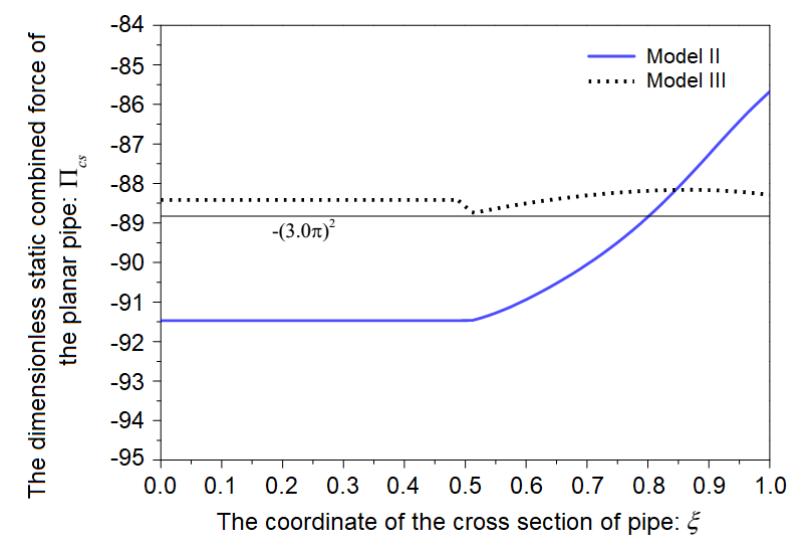

(d) $\bar{u}=3.0 \pi$

Figure 6. The variation curves of the static axial force of the pinned-sliding bearing-pinned pipe with the location of the cross section of the pipe.

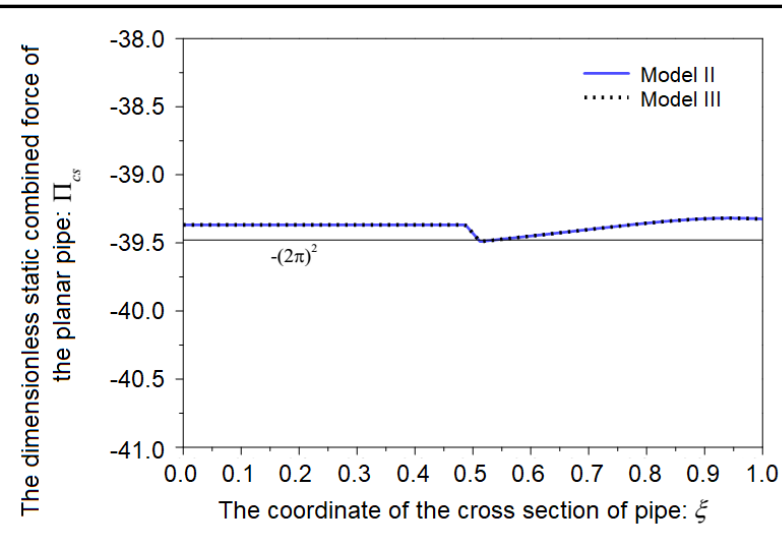

(a) $\bar{u}=2 \pi$

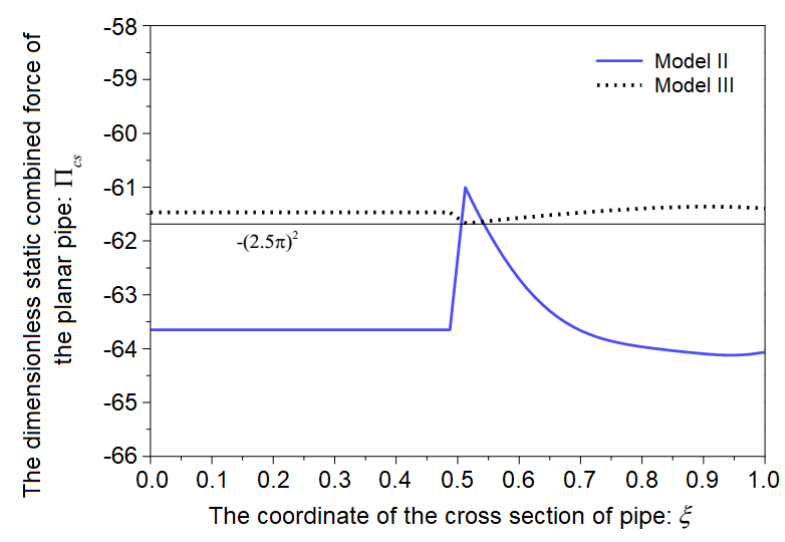

(b) $\bar{u}=2.5 \pi$

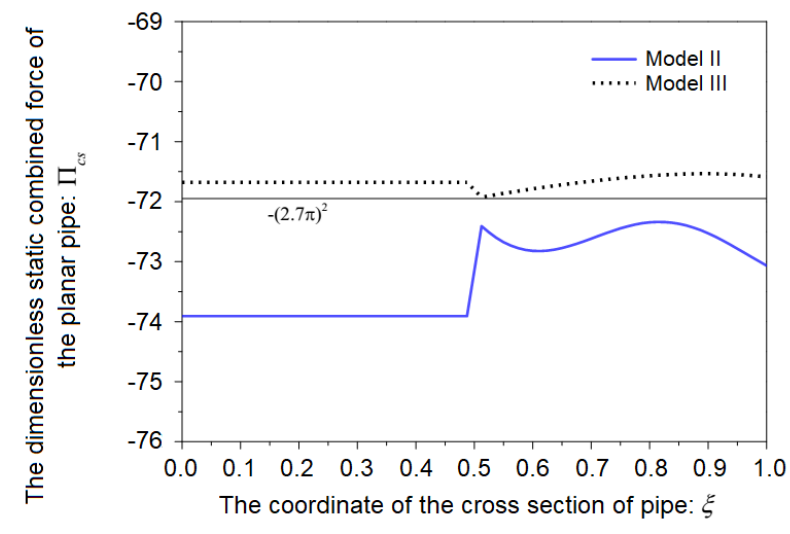

(c) $\bar{u}=2.7 \pi$

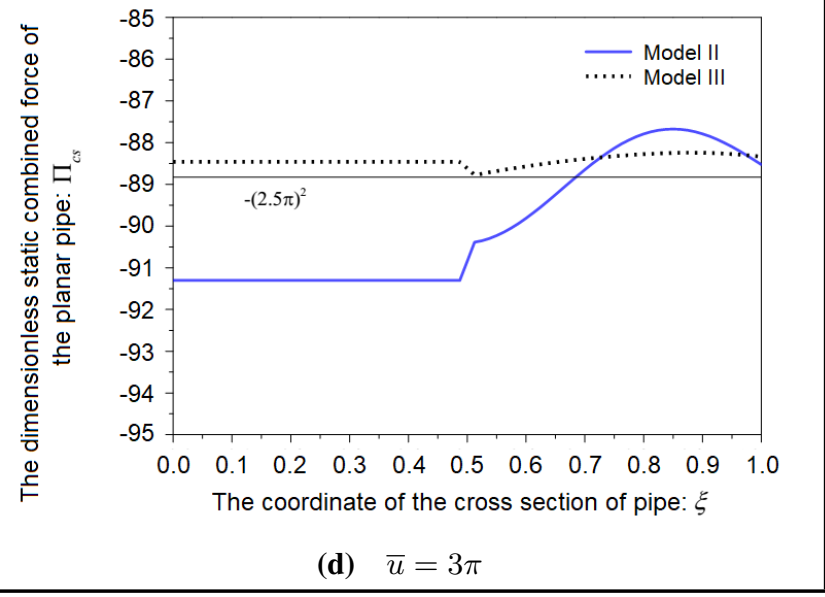

Figure 7. The variation curves of the static axial force of the pinned-pinned pipe with the location of the cross section of the pipe. 
the derivation of Eq. (27), it is assumed that the axial elongation caused by the radial displacement $v$ is $-v d \theta,{ }^{25}$ which is distinct with the actual situation. For the above two reasons, the phenomenon that the static deformation is continuous (as shown in Figs. 3 and 4) but the axial force is not continuous occurs.

\subsection{The Stability of the Straight-Curved Pipe Conveying Fluid}

From the motion equations of the four theoretical models in the Table 1, the finite element equations of the straight pipe and the curved pipe could be derived as Eqs. (50) and (59) respectively. Using the element integration method, the finite element equation to calculate the natural frequencies of the straightcurved pipe conveying fluid could be obtained:

$$
[M]_{d}\{\ddot{\eta}\}_{d}+[D]_{d}\{\dot{\eta}\}_{d}+[K]_{d}\{\eta\}_{d}=0 ;
$$

where $[M]_{d},[D]_{d}$ and $[K]_{d}$ are the total mass matrix, total damping matrix and total stiffness matrix respectively.

The dimensionless eigenvalue $\omega$ of the straight-curved pipe conveying fluid is

$$
\omega=\left(\frac{M_{f}+M_{t}}{E I}\right)^{1 / 2} \Omega L^{2}
$$

where $\Omega$ is the circular frequency of the straight-curved pipe conveying fluid. Generally, the eigenvalues $\omega$ is a plural. According to the positive and negative of the real part of the eigenvalue $\omega$, the stability of the system can be analyzed. ${ }^{3,9}$

The first-order eigenvalue of the pinned-pinned-pinned straight-curved pipe conveying fluid varying with flow velocity is shown in Fig. 8.

From the results of the static deformation of the pipe calculated by using the theoretical model II-III, a mutation occurs in the static deformation when the flow velocity reaches a certain value. However, the changing curves of the eigenvalues of the straight-curved pipe conveying fluid system are still continuous with increasing the flow velocity, which is different from the result of literature. ${ }^{22}$ It could be explained that when the static deformation of the pipe is abrupt, the static axial force of the curved segment does not change much, and the magnitude of the difference between the values of static axial force and $-(\bar{u})^{2}$ is still within $10^{0}$. The frequency of the straight-curved pipe conveying fluid system is not sensitive to the degree of the change of the static deformation.

The eigenvalues show that the buckling instability of the first-order mode occurs when the flow velocity reaches a certain value. The critical flow velocity in the theoretical model I and Koo and Yoo's theoretical model ${ }^{24}$ is $2.5 \pi$. The critical flow velocity in the theoretical model II-III is $2.6 \pi$. The critical flow velocity in the theoretical model IV is $2.7 \pi$. Therefore, when the vibration characteristics of the pinned-pinnedpinned straight-curved pipe conveying fluid are qualitatively studied, the four theoretical models proposed in this paper and Koo and Yoo's theoretical mode ${ }^{24}$ are all right. By considering the static deformation and the geometric nonlinear deformation of the pipe, the additional axial force of straight pipe segment can only improve the accuracy of calculation.

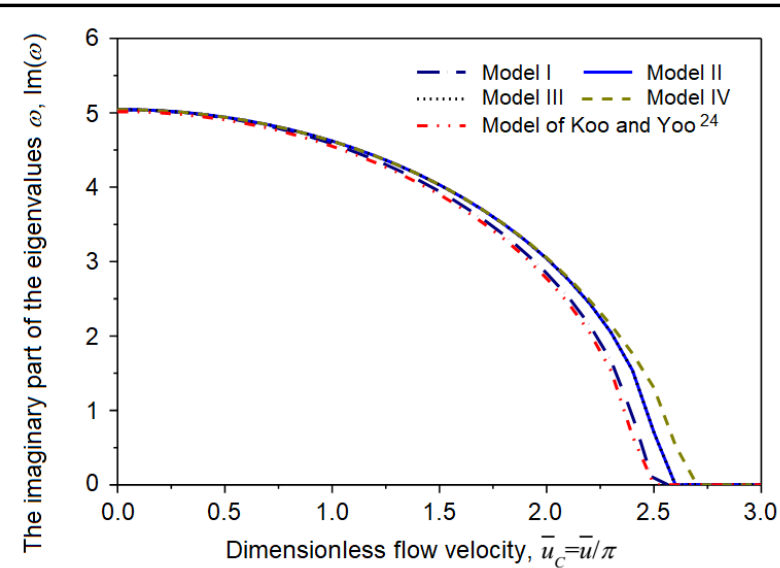

(a)

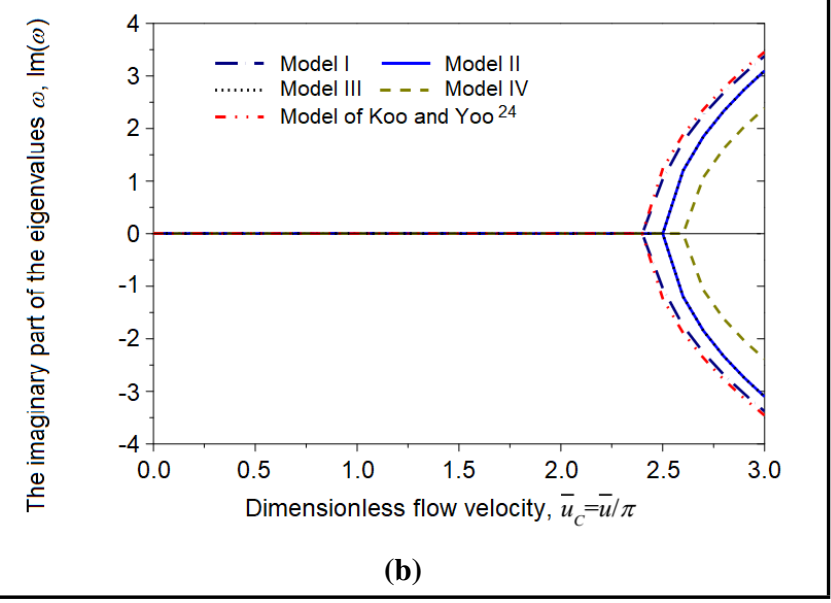

Figure 8. Curves of the first-order eigenvalue of the pinned-pinned-pinned straight-curved pipe conveying fluid varying with flow velocity.

The first-order eigenvalue of the pinned-sliding bearingpinned straight-curved pipe conveying fluid varying with the flow velocity is shown in Fig. 9.

It can be seen that the results calculated by the theoretical model I and Koo and Yoo's model ${ }^{24}$ are consistent. The results show that when $\bar{u}=2.5 \pi$, the buckling instability of the firstorder mode occurs. The results calculated by the theoretical models II-III are consistent. Their results show that the firstorder frequency of the straight-curved pipe system changes little with the increase of the flow velocity, and the real part of the first-order eigenvalue of the system is 0 , so the system is stable.

Therefore, when the vibration characteristics of the pinnedsliding bearing-pinned straight-curved pipe conveying fluid is studied, it is necessary to consider the static deformation of the pipe system, while it is not necessary to consider the geometric nonlinear deformation of the pipe.

The first-order eigenvalue of the pinned-pinned straightcurved pipe conveying fluid varying with the flow velocity is shown in Fig. 10. The results calculated by the theoretical model I show that with the increase of flow velocity, the straight-curved pipe system experiences a flutter instability with the first-order modal, but the critical flow velocity cannot be determined. The results calculated by Koo and Yoo's theoretical mode ${ }^{24}$ show that the straight-curved pipe system occurs a buckling instability with the first-order modal when $\bar{u}=1.8 \pi$. The results calculated by the theoretical models 


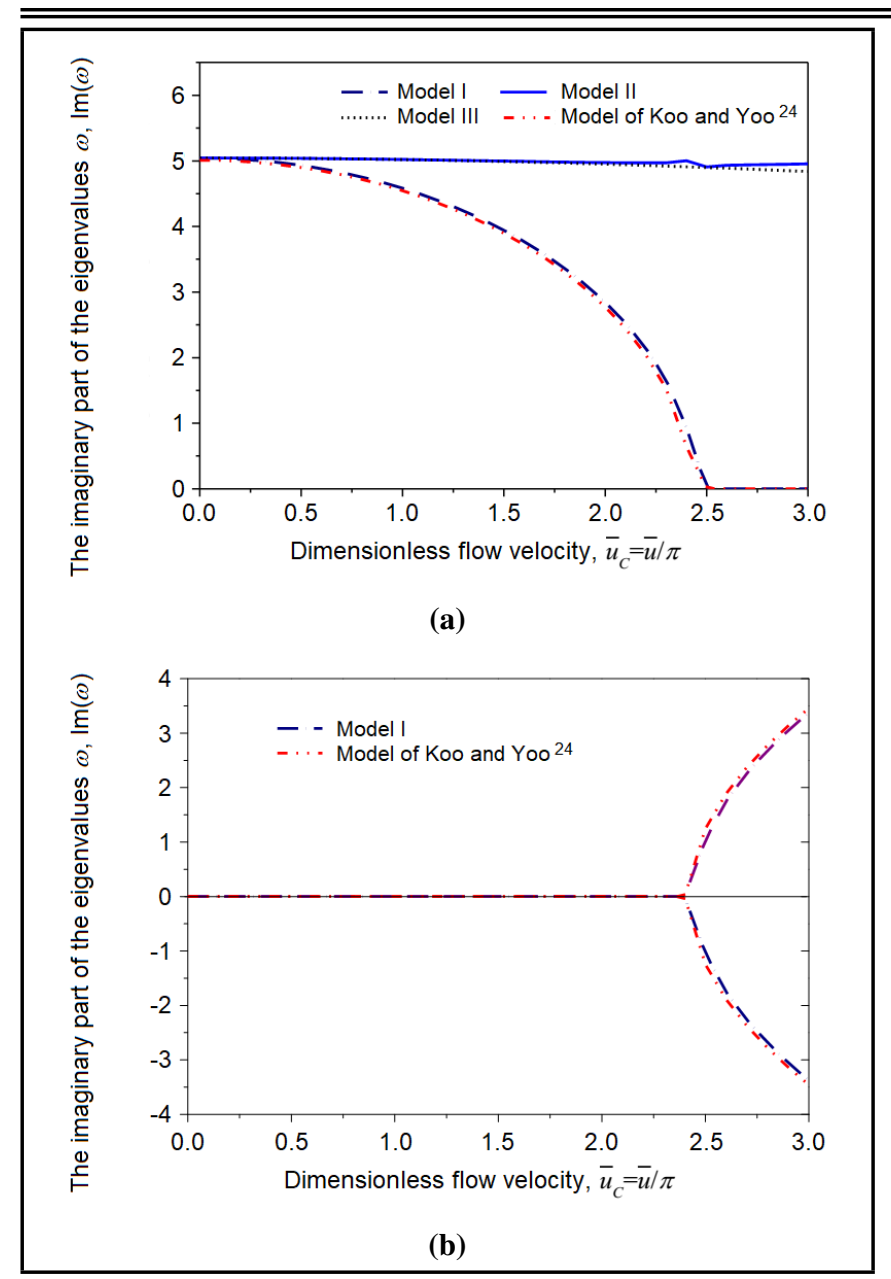

Figure 9. The variation curves of the first-order eigenvalue of the pinnedsliding bearing-pinned straight-curved conveying fluid varying with the flow velocity.

II-III are consistent. Their results show that the first-order frequency of the straight-curved pipe system changes little with the increase of the flow velocity, and the real part of the firstorder eigenvalue of the system is 0 , so the system is stability.

Therefore, when the vibration characteristics of the pinnedpinned straight-curved pipe conveying fluid is studied, it is necessary to consider the static deformation of the system, while it is not necessary to consider the geometric nonlinear deformation of the pipe.

\section{CONCLUSIONS}

In this paper, the dynamic theoretical model for solving the vibration characteristics of the straight-curved pipe conveying fluid was studied and the following conclusions were drawn:

(1) The geometric nonlinear deformation of pipe and the nonlinear force caused by the bend deformation of the straight pipe segment had a great influence on the calculation of the static deformation of the pipe system, while they had little influence on the calculation of the natural frequency of the pipe system.

(2) When the natural frequency of the pipe system was calculated, the static deformation of the system was considered depending on the situation of the restraint of the system. When the natural frequencies of the pinnedpinned pipe or the pinned-sliding bearing-pinned pipe

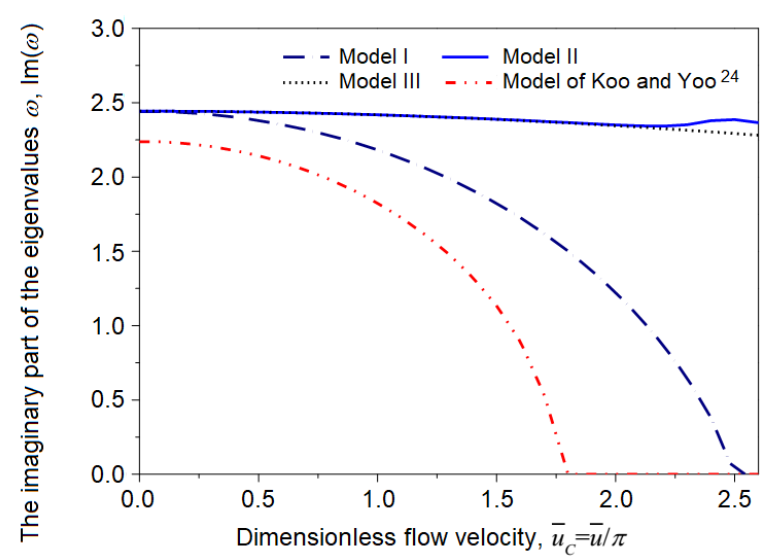

(a)

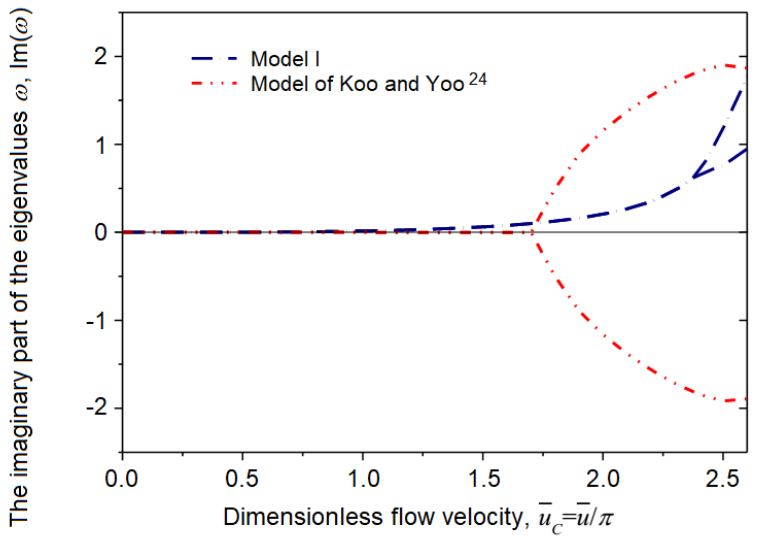

(b)

Figure 10. The variation curve of the first-order eigenvalue of the pinnedpinned straight-curved pipe conveying fluid varying with the flow velocity.

were solved, the static deformation of the pipes must be considered. When the natural frequencies of the pinnedpinned-pinned pipe were solved, the static deformation of the pipe could be ignored.

(3) When the fluid flows through the curved pipe, the pipe system would undergo static deformation. In this case, the value of the static axial force of the pipe was approximately the square of the flow velocity. In addition, the change of the static axial force of the pipe within the magnitude of $10^{\circ}$ had no influence on the calculation of the frequency of the system. Therefore, the square of flow velocity could be used as the static axial force of the pipe and could be substituted into the equation of motion of the pipe about the static equilibrium position so as to simplify the theoretical models.

(4) The stability of the pipe system was related to the boundary conditions. When both ends of the pipe and the connecting point between the straight pipe segment and the curved pipe segment were pinned, the first-order modal buckling instability occurred. The system maintained stability when there was a pinned constraint on the two end points of the pipe and there was a sliding bearing or a nonconstraint on the connection point between the straight pipe segment and the curved pipe segment. 


\section{ACKNOWLEDGEMENTS}

This work is supported by the National Natural Science Foundation of China (Grant Nos: 11772273); the Opening Project of Sichuan Province University Key Laboratory of Bridge Non-destruction Detecting and Engineering Computing, China (Grant Nos: 2016QZJ03). Fund Project of Sichuan University of Science \& Engineering in hit-haunting for talents, China (Grant Nos: 2016RCL31). The authors are grateful to the anonymous reviewers whose work greatly improved this paper.

\section{REFERENCES}

1 Paidoussis, M. P. Flutter of Conservative Systems of Pipes Conveying Incompressible Fluid, ARCHIVE Journal of Mechanical Engineering Science 1959-1982 (vols 1-23), 17 (1), 19-25, (1975). https://dx.doi.org/10.1243/JMES_JOUR_1975_017_005_02

2 Dai, H. L., Wang, L., Qian, Q., and Gan, J. Vibration analysis of three-dimensional pipes conveying fluid with consideration of steady combined force by transfer matrix method, Applied Mathematics and Computation, 219 (5), 2453-2464, (2012). https://dx.doi.org/10.1016/j.amc.2012.08.081

3 Wen, H. B., Yang, Y. R., Li, P., Li, Y. D., and Huang, Y. A New Method Based on Laplace Transform and Its Application to Stability of Pipe Conveying Fluid, Shock and Vibration, 2017 (3), 1-9, (2017). https://dx.doi.org/10.1155/2017/1472601

4 Rahmati, M., Mirdamadi, H. R., and Goli, S. Divergence instability of pipes conveying fluid with uncertain flow velocity, Physica A: Statistical Mechanics and Its Applications, 491, 650-665, (2017). https://dx.doi.org/10.1016/j.physa.2017.09.022

5 Holmes, P. J. Bifurcations to divergence and flutter in flow-induced oscillations: A finite dimensional analysis, Journal of Sound and Vibration, 53 (4), 471-503, (1977). https://dx.doi.org/10.1016/0022-460X(77)90521-1

6 Holmes, P. J. Pipes supported at both ends cannot flutter, Journal of Applied Mechanics, 45 (3), 619-622, (1978). https://dx.doi.org/10.1115/1.3424371

7 Łuczko, J. and Czerwiński, A. Nonlinear three-dimensional dynamics of flexible pipes conveying fluids, Journal of Fluids and Structures, 70, 235-260, (2017). https://dx.doi.org/10.1016/j.jfluidstructs.2017.02.002

8 Czerwiński, A. and Łuczko, J. Non-planar vibrations of slightly curved pipes conveying fluid in simple and combination parametric resonances, Journal of Sound and Vibration, 413, 270-290, (2018). https://dx.doi.org/10.1016/j.jsv.2017.10.026

9 Qi, H. H. and Xu, J. Effect of Galerkin modal truncation on natural frequency analysis of a cantilevered pipe conveying fluid, Journal of Vibration and Shock, 30 (1), 148-151, (2011). https://dx.doi.org/10.3969/j.issn.10003835.2011 .01 .033
10 Ghayesh, M. H., Païdoussis, M. P., and ModarresSadeghi, Y. Three-dimensional dynamics of a fluidconveying cantilevered pipe fitted with an additional spring-support and an end-mass, Journal of Sound and Vibration, 330 (12), 2869-2899, (2011). https://dx.doi.org/10.1016/j.jsv.2010.12.023

11 Ghayesh, M. H., Païdoussis, M. P., and Amabili, M. Nonlinear dynamics of cantilevered extensible pipes conveying fluid, Journal of Fluids and Structures, 332, 6405-6418, (2013). https://dx.doi.org/10.1016/j.jsv.2013.06.026

12 Askarian, A. R., Haddadpour, H., Firouz-Abadi, R. D., and Abtahi, H. Nonlinear dynamics of extensible viscoelastic cantilevered pipes conveying pulsatile flow with an end nozzle, International Journal of Non-Linear Mechanics, 91, 22-35, (2017). https://dx.doi.org/10.1016/j.ijnonlinmec.2017.02.003

13 Chen, S. S. Flow-induced in-plane instabilities of curved pipes, Nuclear Engineering and Design, 23 (1), 29-38, (1972). https://dx.doi.org/10.1016/0029-5493(72)90189-6

14 Chen, S. S. Vibration and Stability of a Uniformly Curved Tube Conveying Fluid, Journal of the Acoustical Society of America, 51 (1B), 223-232, (1972). https://dx.doi.org/10.1121/1. 1912834

15 Misra, A. K., Païdoussis, M. P., and Van, K. S. On the dynamics of curved pipes transporting fluid, Part I: Inextensible theory, Journal of Fluids and Structures, 2 (3), 221-244, (1988). https://dx.doi.org/10.1016/S08899746(88)80009-4

16 Misra, A. K., Païdoussis, M. P., and Van, K. S. On the dynamics of curved pipes transporting fluid, Part II: extensible theory, Journal of Fluids and Structures, 2 (3), 245-261, (1988). https://dx.doi.org/10.1016/S08899746(88)80010-0

$17 \mathrm{Ni}$, Q., Wang, L., and Qian, Q. Bifurcations and chaotic motions of a curved pipe conveying fluid with nonlinear constraints, Computers \& Structures, 84 (10-11), 708-717, (2006). https://dx.doi.org/10.1016/j.compstruc.2005.11.006

18 Wang, L., Ni, Q., and Huang, Y. Y. GDQR for the analysis of flow-induced vibrations of curved pipes conveying fluid, Journal of Dynamics and Control, 3 (1), 72-77, (2005). https://dx.doi.org/10.3969/j.issn.1672-6553.2005.01.015

19 Wang, L., Ni, Q., and Huang, Y. Y. Chaotic vibration and suppression of a fluid-conveying curved pipe by considering the effect of internal fluid pressure, Journal of Dynamics and Control, 4 (3), 221-226, (2006). https://dx.doi.org/10.3969/j.issn.1672-6553.2006.03.006

20 Wang, L. and Ni, Q. Vibration bifurcations of a curved pipe conveying fluid with nonlinear constraint, Journal of Vibration and Shock, 25 (1), 67-69, (2006). https://dx.doi.org/10.3969/j.issn.1000-3835.2006.01.017 
${ }^{21} \mathrm{Ni}$, Q., Wang, L., Huang, Y. Y., and He, Y. Chaotic vibration of a fluid-conveying curved pipe subjected to harmonic excitation, Acta Mechanica Solid Sinica, 26 (3), 249-255, (2005). https://dx.doi.org/10.3969/j.issn.02547805.2005.03.001

22 Jung, D. and Chung, J. A steady-state equilibrium configuration in the dynamic analysis of a curved pipe conveying fluid, Journal of Sound and Vibration, 294 (1-2), 410-417, (2006). https://dx.doi.org/10.1016/j.jsv.2005.11.016

${ }^{23}$ Koo, G. H. and Park, Y. S. Vibration analysis of a 3-dimensional piping system conveying fluid by wave approach. International International Journal of Pressure Vessels and Piping, 67 (3), 249-256, (1996). https://dx.doi.org/10.1016/0308-0161(95)00022-4

${ }^{24}$ Koo, G. H. and Yoo, B. Dynamic characteristics of KALIMER IHTS hot leg piping system conveying hot liquid sodium, International Journal of Pressure Vessels and Piping, 77 (11), 679-689, (2000). https://dx.doi.org/10.1016/S0308-0161(00)00057-0

25 Timoshenko, S. P., Gere, J. M. Theory of Elastic Stability, McGraw-Hill, New York, (1961).

\section{APPENDIX A}

Integrals $\left[J_{i}\right]$ are defined as follows:

$$
\begin{array}{rlrl}
{\left[J_{1}\right]} & =\int_{0}^{\zeta_{e}}\left[\Phi_{1}\right]^{T}\left[\Phi_{1}\right]^{\prime} d \zeta ; & {\left[J_{2}\right]=\int_{0}^{\zeta_{e}}\left[\Phi_{2}\right]^{\prime \prime T}\left[\Phi_{2}\right]^{\prime \prime} d \zeta ;} \\
{\left[J_{3}\right]=\int_{0}^{\zeta_{e}}\left[\Phi_{2}\right]^{\prime T}\left[\Phi_{2}\right]^{\prime} d \zeta ;} & {\left[J_{4}\right]=\int_{0}^{\zeta_{e}}\left[\Phi_{1}\right]^{\prime T}\left[\Phi_{2}\right] d \zeta ;} \\
{\left[J_{5}\right]=\int_{0}^{\zeta_{e}}\left[\Phi_{1}\right]^{\prime T}\left[\Phi_{2}\right]^{\prime \prime} d \zeta ;} & {\left[J_{6}\right]=\int_{0}^{\zeta_{e}}\left[\Phi_{1}\right]^{T}\left[\Phi_{2}\right]^{\prime} d \zeta ;} \\
{\left[J_{7}\right]=\int_{0}^{\zeta_{e}}\left[\Phi_{1}\right]^{T}\left[\Phi_{1}\right] d \zeta ;} & {\left[J_{8}\right]=\int_{0}^{\zeta_{e}}\left[\Phi_{2}\right]^{\prime \prime T}\left[\Phi_{1}\right]^{\prime} d \zeta ;} \\
{\left[J_{9}\right]=\int_{0}^{\zeta_{e}}\left[\Phi_{2}\right]^{T}\left[\Phi_{2}\right]^{\prime \prime} d \zeta ;} & {\left[J_{10}\right]=\int_{0}^{\zeta_{e}}\left[\Phi_{2}\right]^{T}\left[\Phi_{1}\right]^{\prime} d \zeta ;} \\
{\left[J_{11}\right]=\int_{0}^{\zeta_{e}}\left[\Phi_{2}\right]^{T}\left[\Phi_{2}\right] d \zeta ;} & {\left[J_{12}\right]=\int_{0}^{\zeta_{e}}\left[\Phi_{1}\right]^{T}\left[\Phi_{1}\right]^{\prime} d \zeta ;} \\
{\left[J_{13}\right]=\int_{0}^{\zeta_{e}}\left[\Phi_{2}\right]^{T}\left[\Phi_{2}\right]^{\prime} d \zeta ;} & {\left[J_{14}\right]=\int_{0}^{\zeta_{e}} \xi\left[\Phi_{2}\right]^{\prime T}\left[\Phi_{2}\right]^{\prime} d \zeta ;} \\
{\left[J_{15}\right]=\int_{0}^{\zeta_{e}}\left[\Phi_{2}\right]^{\prime T}\left[\Phi_{1}\right]^{\prime} d \zeta ;} & {\left[J_{16}\right]=\int_{0}^{\zeta_{e}} \zeta\left[\Phi_{2}\right]^{\prime T}\left[\Phi_{1}\right]^{\prime} d \zeta ;} \\
{\left[J_{17}\right]=\int_{0}^{\zeta_{e}}\left[\Phi_{1}\right]^{T}\left[\Phi_{2}\right] d \zeta ;} & {\left[J_{18}\right]=\int_{0}^{\zeta_{e}}\left[\Phi_{2}\right]^{T}\left[\Phi_{1}\right] d \zeta ;} \\
{\left[J_{19}\right]=\int_{0}^{\zeta_{e}} \xi\left[\Phi_{1}\right]^{T}\left[\Phi_{2}\right]^{\prime} d \zeta ;} & {\left[J_{20}\right]=\int_{0}^{\zeta_{e}} \zeta\left[\Phi_{1}\right]^{T}\left[\Phi_{1}\right] d \zeta ;}
\end{array}
$$

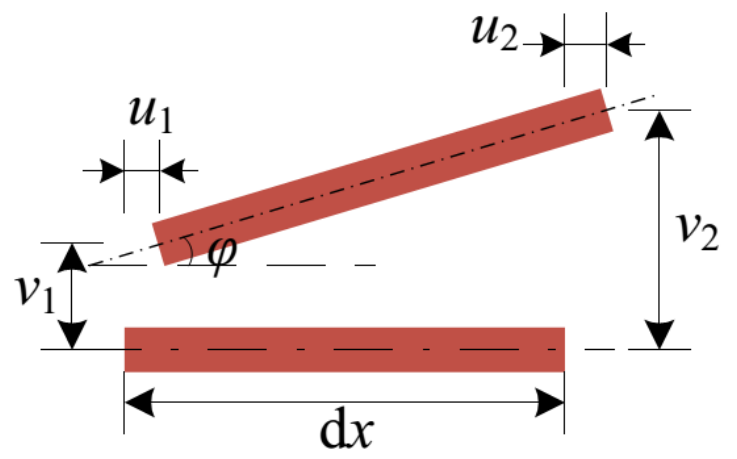

Figure B-1. The diagrammatic drawing of the elongation of the infinitesimal segment of the straight pipe.

$$
\begin{array}{ll}
{\left[J_{21}\right]=\int_{0}^{\zeta_{e}} \zeta\left[\Phi_{1}\right]^{T}\left[\Phi_{1}\right]^{\prime} d \zeta ;} & {\left[J_{22}\right]=\int_{0}^{\zeta_{e}} \zeta\left[\Phi_{1}\right]^{T}\left[\Phi_{2}\right] d \zeta ;} \\
{\left[J_{23}\right]=\int_{0}^{\zeta_{e}}\left[\Phi_{2}\right]^{\prime \prime T}\left[\Phi_{1}\right]^{\prime} d \zeta ;} & {\left[J_{24}\right]=\int_{0}^{\zeta_{e}} \zeta\left[\Phi_{2}\right]^{T}\left[\Phi_{2}\right]^{\prime} d \zeta ;} \\
{\left[J_{25}\right]=\int_{0}^{\zeta_{e}} \zeta\left[\Phi_{2}\right]^{T}\left[\Phi_{1}\right] d \zeta ;} & {\left[J_{26}\right]=\int_{0}^{\zeta_{e}}\left[\Phi_{2}\right]^{T T}\left[\Phi_{2}\right] d \zeta ;} \\
{\left[J_{27}\right]=\int_{0}^{\zeta_{e}} \zeta\left[\Phi_{2}\right]^{\prime T}\left[\Phi_{2}\right] d \zeta ;} & {\left[J_{28}\right]=\int_{0}^{\zeta_{e}} \xi\left[\Phi_{2}\right]^{T}\left[\Phi_{2}\right]^{\prime \prime} d \zeta ;} \\
{\left[J_{29}\right]=\int_{0}^{\zeta_{e}} \zeta\left[\Phi_{2}\right]^{T}\left[\Phi_{1}\right]^{\prime} d \zeta ;} & {\left[J_{30}\right]=\int_{0}^{\zeta_{e}}\left[\Phi_{1}\right]^{T}\left[\Phi_{2}\right]^{\prime} d \zeta ;} \\
{\left[J_{31}\right]=\int_{0}^{\zeta_{e}} \zeta\left[\Phi_{1}\right]^{\prime T}\left[\Phi_{2}\right]^{\prime} d \zeta ;} & {\left[J_{32}\right]=\int_{0}^{\zeta_{e}} \zeta^{2}\left[\Phi_{2}\right]^{T}\left[\Phi_{2}\right]^{\prime} d \zeta}
\end{array}
$$

\section{APPENDIX B}

Take the infinitesimal segment of the straight pipe, with the axial displacement of the two ends not being constrained at the same time, as is shown in Fig. B-1. The elongation of the infinitesimal segment is

$$
d s=\frac{1-\cos \varphi}{\cos \varphi} d x+\frac{1}{\cos \varphi}\left(u_{2}-u_{1}\right) .
$$

So, the axial force of the infinitesimal segment is

$$
Q_{x}=E A_{t}\left(\frac{1-\cos \varphi}{\cos \varphi}+\frac{1}{\cos \varphi} \frac{\partial u}{\partial x}\right)
$$

According to Eq. (3), the following steady state value of the combined force of the infinitesimal segment can be achieved:

$$
\Pi_{s s}=\Pi_{p}-\mathcal{A}\left(\frac{1-\cos \varphi}{\cos \varphi}+\frac{1}{\cos \varphi} \eta_{1 s}^{\prime}\right) .
$$

